\title{
La Fuerza Aérea Mexicana y su Papel en la Lucha Contra el Tráfico Aéreo Ilegal de Narcóticos
}

Alfredo Fernández de Lara

\section{Introducción}

El presente capítulo tiene como objetivo analizar el papel que ha desempeñado, sobre todo en las últimas dos décadas, la Fuerza Aérea Mexicana (FAM) en la lucha contra el tráfico aéreo ilegal de narcóticos. Con este fin, en la primera parte del capítulo se realiza una breve contextualización histórica de la evolución que se ha presentado en el combate al tráfico de drogas por parte de las Fuerzas Armadas Mexicanas. Posteriormente, se analiza la evolución que ha tenido la FAM y, en especial, el surgimiento y desarrollo que ha tenido el Sistema de Vigilancia Aérea de México (SIVA) y el proceso que se ha seguido para proveer a la FAM de las capacidades necesarias para la implementación de operaciones de interdicción aérea. Finalmente, desde una perspectiva de política comparada, se hace un recuento de la estrecha cooperación bilateral que existe entre la Fuerza Aérea Colombiana (FAC) y la Fuerza Aérea Mexicana para hacer frente al crimen transnacional y las operaciones aéreas ilegales. 


\section{Antecedentes}

El origen de la Fuerza Aérea Mexicana (FAM) se remonta a la época de la Revolución mexicana. Específicamente data del 5 de febrero de 1915 cuando el Jefe del Ejército Constitucionalista, Venustiano Carranza, expidió en Faros (Veracruz) el decreto por el que se creaba la denominada arma de Aeronáutica Militar. Ésta quedó bajo el mando del entonces Mayor del Estado Mayor Alberto Salinas Carranza, pero no fue sino hasta mayo del mismo año que se iniciaron los trabajos de organización del arma debido a la situación que vivía el país (SEDENA, 2015).

Entre los años cuarenta y los ochenta, la FAM se desarrolló bajo la hipótesis de combate a una guerra externa. En los años cuarenta, en el contexto de la Segunda Guerra Mundial, y en los ochenta, ante el incremento de las tensiones en algunos países de Centroamérica. Desde la década de 1990 la doctrina de guerra aérea se replanteó para misiones internas y los helicópteros se volvieron un instrumento clave, tanto para transporte de personal como para la lucha contra las drogas, contrainsurgencia, rescate de la población y entrenamiento de fuerzas especiales (CIEPAC \& CENCOS, 2000). Desde los años noventa del siglo pasado hasta la actualidad la prioridad de la Secretaría de la Defensa Nacional (SEDENA) y de la FAM ha sido hacer frente al crimen organizado y al tráfico de drogas y, más recientemente, al robo masivo de combustible conocido en México como huachicole ${ }^{48}$.

Entre la Segunda Guerra Mundial y los ańos ochenta el equipo y las aeronaves de la FAM no se sometieron a un proceso amplio de modernización. Sería hasta los años ochenta que se adquirieron 12 aviones F-5E y F-5F supersónicos (diez de una plaza y dos de dos plazas) pertenecientes al Escuadrón Aéreo de Defensa 401, con sede en la Base Aérea de Santa Lucía (Ruiz, 2014). Como parte de este proceso de renovación en 1981 se incorporaron cinco helicópteros Bell 212 y en 1989 se adquirieron 18 unidades más Bell 212 y dos Bell 206L, las cuales se incorporaron al Escuadrón Aéreo de Operaciones Especiales 215 para combate al narcotráfico (Ruiz, 2014).

48 El Presidente de la República instruyó a la Secretaría de la Defensa Nacional para que mediante el Sistema Integral de Vigilancia Aérea, se materialice el concepto operativo para la vigilancia de los ductos de la empresa de Petróleos Mexicanos (PEMEX), empleando Sistemas de Aeronaves Pilotadas a Distancia de la SEDENA, SEMAR, el Centro Nacional de Inteligencia (CNI), la Fiscalía General de la República (FGR), la Policía Federal (PF) y PEMEX, para combatir el robo de hidrocarburos llevando a cabo del 1 de diciembre de 2018 al 31 de julio de 2019, 272 misiones de vigilancia, con un total de 842:45 horas de vuelo (SEDENA, 2020a). 
Hasta el año 2000 el equipo de la FAM se dividía en: aviones de combate, de reconocimiento, de transporte y carga, de entrenamiento y la fuerza transportada vía helicóptero, integrándose como puede observarse en la tabla 5.1:

\section{Tabla 5.1}

Recuento del equipo de la FAM en 2000

\begin{tabular}{|c|c|c|c|}
\hline Cantidad & Tipo de aeronave & Cantidad & Tipo de aeronave \\
\hline 2 & F27 & 2 & King executive aircraft \\
\hline 40 & F33 & 11 & CT-134 A \\
\hline 27 & $\begin{array}{l}\text { T-33-A para contrainsur- } \\
\text { gencia }\end{array}$ & 74 & PC- fighter trainers \\
\hline 14 & Commander 500s & 20 & CAP-10 maneuver trainers \\
\hline 1 & SA 1-37-A & 5 & T-39 \\
\hline 9 & C-130 Hércules & 27 & Aviones helibaldes \\
\hline 2 & $\begin{array}{l}\text { UH-60 Black Hawk } \\
\text { blindados para transporte } \\
\text { y combate }\end{array}$ & 5 & $\begin{array}{l}\text { Bell } 205 \text { Huey II helicópteros } \\
\text { artillados de transporte }\end{array}$ \\
\hline 12 & C-47 & 4 & C-26 \\
\hline 1 & C-54 & 27 & Bell 206 \\
\hline 10 & C-118 & 25 & Bell 212 helicópteros de ataque \\
\hline 2 & $\mathrm{BN}-2$ & 3 & SA-332 helicópteros de transporte \\
\hline 5 & Commander 500 & 6 & S-70-A de transporte \\
\hline 1 & Commander 650 & 22 & MD-530F (Sikorsky) \\
\hline 5 & DC-6 & 10 & MI-8 \\
\hline 5 & Boeing 727 & 6 & MI 17 \\
\hline 12 & IAI-201 & 20 & UH- \\
\hline 8 & $\begin{array}{l}\text { F-5 supersónicos de una } \\
\text { plaza }\end{array}$ & 2 & F-5 supersónicos de dos plaza \\
\hline
\end{tabular}

Nota: Elaboración propia basado en CIEPAC \& CENCOS, 2000.

Sin embargo, durante la presidencia de Felipe Calderón Hinojosa (2006-12), y dada su declaración de guerra en contra del crimen organizado, se presentó un notorio incremento en la inseguridad y la violencia generada por los cárteles del narcotráfico, tanto en contra del Estado como de la población civil. En ese contexto se impulsó la modernización de los cuerpos de seguridad pública y de las Fuerza Armadas (Guevara, 2011), las cuales tuvieron un incremento en su participación en labores de seguridad 
interna. La Fuerza Aérea Mexicana no fue ajena al involucramiento de las Fuerzas Armadas en la lucha contra el narcotráfico y se incrementó notoriamente su participación en operaciones de erradicación de cultivos (aspersión aérea y traslado de tropas) y de vigilancia aérea. En este escenario se impulsó una mayor modernización de las aeronaves de ala fija y rotatoria de las que disponía la Fuerza Aérea. Esta modernización continuó durante la administración del presidente Enrique Peña Nieto (2012-18), también en un contexto de violencia desbordada.

En opinión del analista Ińigo Guevara, la guerra contra el narcotráfico ha tenido una gran influencia en la modernización de las fuerzas armadas mexicanas, incluida la FAM. La guerra entre el Estado y grupos no estatales, más que entre Estados, se ha vuelto una constante en muchas regiones: "los teatros de operaciones también han variado, desde las selvas de Colombia, a las montañas de Afganistán, la costa de Somalia hasta el ciberespacio" (Guevara, 2011). La forma de hacer frente a esas amenazas, tanto internas como externas, también ha vivido una constante evolución hacia el uso de nuevas tecnologías como el combate aéreo no tripulado o los ataques cibernéticos.

En el caso de América Latina, la principal amenaza no proviene de otros actores estatales, la principal amenaza es de orden interno y transnacional, en especial el crimen organizado y el narcotráfico. Este último genera un desafío transnacional que pone en riesgo la seguridad interna y regional. En el caso de Colombia y México, las actividades de las organizaciones criminales y grupos armados al margen de la ley han incidido en la interdependencia que se presenta entre estos países, entendida ésta como "situaciones caracterizadas por efectos recíprocos entre países o entre actores en diferentes países” (Keohane y Nye, 2005). Las relaciones interdependientes siempre implican costos para las partes, aunque no necesariamente son un juego de suma cero (Keohane y Nye, 2005).

De hecho, la interdependencia militar puede ser un juego cooperativo, pues, en realidad los aliados militares procuran que la interdependencia proporcione un aumento de la seguridad para todos (Keohane y Nye, 2005). En el caso del combate al narcotráfico las relaciones bilaterales entre Colombia y México se han centrado en relaciones de cooperación que buscan la solución a problemas comunes, por ejemplo, el tráfico aéreo ilegal de narcóticos. Precisamente, el objetivo de esta investigación busca exponer ¿cuál es el papel de la Fuerza Aérea Mexicana en materia de combate al tráfico aéreo ilegal? ¿¿de qué capacidades dispone en esta materia? y ¿cuál es la relación de cooperación en esta materia con Colombia? 


\section{Breve Recuento del Narcotráfico en México}

En México, el origen del narcotráfico se remonta a la década de 1930, particularmente en entidades federativas como Baja California, Sinaloa y Jalisco. Sin embargo, fue en la década de 1950 que se generó una paulatina centralización en el control de este mercado mediante la colusión entre traficantes y políticos (Astorga, 2016, 2007, Hernández, 2014). Más adelante, por la década de 1980, la lucha contra el narcotráfico comenzó a destacarse en la agenda pública como efecto de los cambios en la política antidrogas en Estados Unidos y de las presiones ejercidas por este país en contra del gobierno mexicano, especialmente, a mediados de los años ochenta después del asesinato de Enrique Camarena, agente de la DEA.

Diversos autores han señalado que en las administraciones federales de los años ochenta y noventa hubo una especie de pacto entre autoridades de gobierno de distintos niveles y los narcotraficantes mediante el cual "la autoridad se encargó de gestionar la organización eficiente y pacífica del mercado, a cambio de la aceptación de impuestos extraídos de la actividad criminal y de la sujeción de las organizaciones criminales a reglas debidamente acordadas" (Palacios y Serrano, 2010, p. 117).

Esta relación de complicidad entre política, fuerzas de seguridad y organizaciones criminales prácticamente se tejió a lo largo del siglo XX, como lo evidencia Luis Astorga (2005), quien respecto al vínculo entre autoridades gubernamentales de todos los niveles y traficantes señala lo siguiente:

Desde los inicios de la formación del campo del tráfico de drogas en México, éste adquirió características particulares, pues nació a la sombra de intereses del campo político y supeditado a él. Así continuó durante décadas. Lo que se modificó con el tiempo fue la mediación entre el campo político y el del tráfico de drogas. El resquebrajamiento progresivo del sistema político posrevolucionario basado en el presidencialismo y en el partido de Estado, el avance de la oposición política en el Congreso y en los gobiernos estatales y, finalmente, la alternancia en el poder, que implicó el desplazamiento de ese partido (PRI) el poder ejecutivo federal mediante elecciones democráticas en el año 2000, crearon por primera vez en México las condiciones de posibilidad para una mayor autonomía relativa del campo del tráfico de drogas respecto al poder político: de allí el recurso a las medidas de excepción actuales, desesperadas, como el uso creciente de las fuerzas armadas, para intentar recuperar los mecanismos 
de contención y control relativo del negocio del tráfico de drogas que habían operado durante años. (2005, pp. 161-162)

En 1988 el presidente Carlos Salinas de Gortari declaró que el combate a las drogas se elevaba a asunto de seguridad nacional. Sin embargo, en la década de 1990, varios casos evidenciaron (vg. el general Jesús Gutiérrez Rebollo, zar antidrogas encarcelado por cooperar con la delincuencia organizada) el alto grado de permeabilidad que la corrupción había generado en las instituciones, generando que para principios del siglo XXI el Estado mexicano se vea envuelto en una "paradójica batalla que no se puede ganar, perder ni dejar de combatir" (Chabat, 2000).

En mayo de 1998, durante la administración del presidente Ernesto Zedillo (1994-2000) y en gran parte debido a las presiones estadounidenses, se anunció un plan para sellar las fronteras norte y sur de México. Para cumplir con dicha labor 16.300 personas, 980 vehículos, 42 aviones, 50 barcos y 23 helicópteros fueron empleados. Sin embargo, la estrategia, implementada conjuntamente con los Estados Unidos, no tuvo efectos significativos en el flujo de drogas hacia los EE. UU., ni afectó la fortaleza de los cárteles (Astorga, 2007).

A partir del año 2000, con la llegada a la presidencia de Vicente Fox (primer presidente de un partido distinto al PRI) el problema del narcotráfico ya era ampliamente visible; sin embargo, aún no se presentaban las tasas de homicidio y la violencia desbordada que México vive desde el 2008 hasta la actualidad. Durante la administración del presidente Fox se implementó una política de blancos prioritarios enfocada a capturar o dar de baja a los líderes de las principales organizaciones criminales. En opinión de Astorga:

Con las capturas de traficantes importantes en el gobierno de Vicente Fox (Benjamín Arellano, la Rana, el June, Albino Quintero Meraz, el Metro, por ejemplo) el Estado logró, en parte, hacer cumplir las leyes vigentes e imponer su autoridad. Esos hechos contribuyeron en su momento a reducir los márgenes de impunidad y de corrupción asociados al negocio de las drogas, y a modificar las percepciones acerca del poder real de dichas organizaciones y la falta de voluntad política - u otro tipo de razones, como la convivencia y la corrupción de alto nivel- para enfrentarlas. (2007, p. 95)

No obstante, el impacto efectivo de estas capturas fue mínimo y en cambió generó desbalances en la correlación de fuerzas entre los cárteles de 
Sinaloa, Tijuana, Juárez y el Golfo. Estas organizaciones se adaptaron a las nuevas circunstancias y continuaron la penetración de las instituciones de seguridad. Incluso algunos analistas alertaron respecto a que esta estrategia beneficiaba las operaciones ilegales de algunos cárteles sobre otros, en especial se señaló como beneficiario al cártel de Sinaloa, liderado por Joaquín Guzmán Loera.

Además de evidenciar la larga y fuerte conexión entre la clase política, cuerpos de seguridad (vg. la extinta Dirección Federal de Seguridad) y narcotraficantes, Astorga $(2007,2016)$ plantea una de las explicaciones que más fuerza ha cobrado para entender las causas de la escalada de violencia en la última década y media, la fragmentación del poder político y el control social que durante décadas concentró el PRI. Tal parece que la transición política en México tuvo entre sus efectos no deseados un desajuste en las redes de corrupción y complicidad existentes, lo cual gestó las condiciones para el aumento de la autonomía de estas organizaciones criminales, la competencia entre estas y la escalada en la violencia del crimen organizado para hacer frente a la nueva coyuntura política.

Desde la alternancia política en México (2000), las organizaciones criminales mutaron, diversificaron sus actividades ilícitas y se adecuaron a la nueva coyuntura de fragmentación del poder político a nivel local, estatal y federal, reorganizando sus redes de apoyo a nivel federal y subnacional. En lo que respecta a la estrategia de capturar a los principales líderes de los cárteles, ésta no contribuyo a reducir sus actividades ni la violencia que generan, sólo modificó momentáneamente la estructura de algunas organizaciones, los obligó a buscar nuevas estrategias y a replegarse por algún tiempo (Astorga, 2007).

Si bien es cierto que las actividades del narcotráfico en México no son una cuestión nueva, desde el año 2008 se presentó una escalada en la frecuencia y visibilidad de la violencia (expresada en el incremento del número de homicidios atribuidos al crimen organizado) como resultado de la guerra contra el narcotráfico (Márquez y Meyer, 2010) declarada por el presidente Felipe Calderón ${ }^{49}$. Esta violencia continuó en la presidencia de Enrique Peńa Nieto (2012-18) y en la del presidente Andrés Manuel López Obrador (2018-24)

49 "La guerra de Calderón" -como se le llama por simplificar aquello- sumió regiones enteras del país en dinámicas de violencia y descomposición extremas, con miles de muertos, desaparecidos (Márquez \& Meyer, 2010). La declaración de guerra de Calderón, la cual, según coinciden la mayoría de los autores, se realizó de manera improvisada, ya que no delineó una auténtica política de prevención del crimen organizado, ni se definió cuando los militares retornarán a los cuarteles (Guerrero, 2011; Crisis Group, 2013). 
incluso se ha llegado a un número de homicidios dolosos de 35,588 personas en 2019, tal y como se evidencia en la figura 5.1.

\section{Figura 5.1}

\section{Histórico de homicidios dolosos en México, 2000-19}

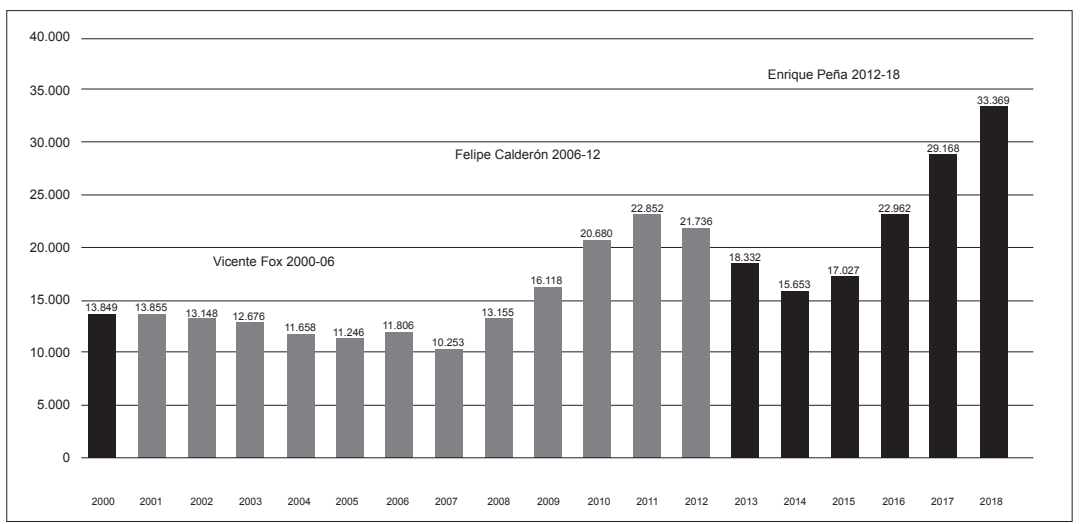

Nota: Elaboración propia a partir de datos del Secretariado Ejecutivo del Sistema Nacional de Seguridad Pública

Desde comienzos del siglo XXI, las organizaciones del narcotráfico más poderosas habían acumulado tantos miembros, armamento, movilidad y liderazgo como para estar en capacidad de desafiar e intimidar a las fuerzas policiales municipales y estatales, sobre todo en zonas de producción de drogas y a lo largo de las principales rutas de contrabando en los estados del norte del país. La ominosa novedad era que algunas organizaciones de traficantes de drogas se mostraban cada vez más dispuestas a retar al Ejército, último muro de protección del Estado mexicano (Bailey, 2014, p. 16). El tráfico de armas provenientes de EE. UU. ha incidido en que las organizaciones criminales dispongan de un fuerte poder de fuego para hacer frente al Estado. Además, se ha identificado que algunas organizaciones criminales mexicanas han recibido asesoría en técnicas de combate, secuestro y tortura por parte de organizaciones criminales de Colombia, incluso se determinó que integrantes del cártel Jalisco Nueva Generación recibieron entrenamiento por parte de las Farc en Colombia ${ }^{50}$. A su vez, se ha identificado la presencia de organizaciones criminales mexicanas en territorio colombiano.

50 Semana. (8 de noviembre de 2018). Los narcomercenarios colombianos en México. SEMA$N A$. Recuperado de https://www.semana.com/nacion/articulo/mercenarios-colombianos-entrenan-integrantes-de-carteles-mexicanos/579046. 
La situación geopolítica de México también incide en el problema, ya que el compartir frontera con un país que históricamente ha sido el principal mercado para drogas ilegales, dado el gran número de consumidores ${ }^{51}$ de marihuana, cocaína, fentanilo ${ }^{52}$, drogas sintéticas, entre otros narcóticos, hace que los incentivos que tienen los cárteles de tráfico de drogas para continuar sus actividades ilícitas transnacionales sean altos. En el caso de México, según cifras de la SEDENA, la marihuana fue la droga ilícita más asegurada o incautada entre 2012 y 2019, seguida de la metanfetamina y cocaína, como lo muestra la figura 5.2.

\section{Figura 5.2}

Incautaciones de drogas ilícitas reportadas por la SEDENA, 2012-19

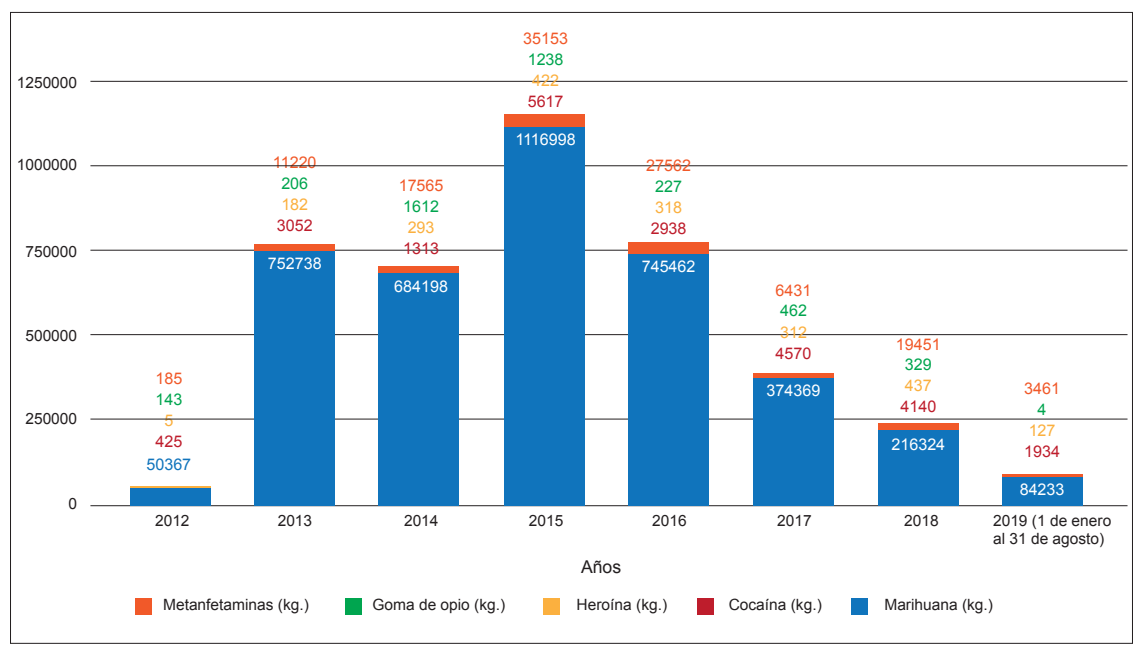

Nota: Datos Abiertos Secretaría de la Defensa Nacional, 2019. Resultados de las operaciones en atención al Narcotráfico.

51 "Se calcula que, en el 2011, unos 22.5 millones de personas en los Estados Unidos de 12 años de edad o mayores usaron alguna droga ilícita o abusaron de medicamentos psicoterapéuticos (como analgésicos, estimulantes o tranquilizantes) en el mes anterior a la encuesta. Esto equivale al 8.7 por ciento de la población, mientras que en el 2002, el porcentaje fue del 8.3 por ciento. El incremento refleja principalmente un aumento reciente en el consumo de la marihuana, la droga ilícita que se consume con más frecuencia”. (National Institute of Drug Abuse, 2013).

52 "En la actualidad los opioides sintéticos —incluido el fentanilo— son las drogas más comúnmente asociadas con las muertes por sobredosis en Estados Unidos. En 2017, el fentanilo fue parte del $59.8 \%$ de las muertes relacionadas con opioides, comparado con el $14.3 \%$ en 2010”. (National Institute of Drug Abuse, 2019). 
Entre las cifras proporcionadas por la SEDENA, como parte de los resultados en operaciones contra el narcotráfico, se muestra que entre 2012 y 2019 se han asegurado 139 aeronaves por actividades relacionadas con el tráfico de drogas y se han localizado 1638 pistas de aterrizaje, datos discriminados en la tabla 5.2. Esto indica que el espacio aéreo mexicano presenta una alta actividad de aeronaves dedicadas al trasiego ilegal de narcóticos, tanto al interior del país como hacia los Estados Unidos de América.

\section{Tabla 5.2}

Vehículos asegurados y pistas clandestinas de aterrizaje localizadas por la SEDENA 2012-19

\begin{tabular}{|c|c|c|c|c|}
\hline Ańos & Terrestres & Aeronaves & Embarcaciones & $\begin{array}{c}\text { Pistas clandestinas } \\
\text { de aterrizaje } \mathrm{e}^{2}\end{array}$ \\
\hline 2012 & 879 & 4 & 3 & 19 \\
\hline 2013 & 8876 & 19 & 20 & 188 \\
\hline 2014 & 8141 & 14 & 8 & 354 \\
\hline 2015 & 9035 & 22 & 8 & 446 \\
\hline 2016 & 5973 & 30 & 14 & 326 \\
\hline 2017 & 11802 & 19 & 16 & 142 \\
\hline 2018 & 10868 & 12 & 6 & 105 \\
\hline $\begin{array}{c}2019 \\
\text { (1 enero al } 31 \\
\text { de agosto })\end{array}$ & 6 & 19 & 4 & 58 \\
\hline Total & 55580 & 139 & 79 & 1638 \\
\hline
\end{tabular}

Nota: Datos Abiertos Secretaría de la Defensa Nacional, 2019. Resultados de las operaciones en atención al Narcotráfico.

\section{El Rol de la Fuerza Aérea Mexicana en el Combate al Narcotráfico}

Según afirman fuentes oficiales estadounidenses, ese país es el mayor consumidor mundial de cocaína, por lo que el tráfico hacia ese país se ha presentado a través de diversas rutas. Sin embargo, con las operaciones de interdicción aérea realizadas en el Caribe, desde mediados de los años ochenta, México se convirtió en el principal país de tránsito utilizado por los trafican- 
tes para transportar cocaína producida en América del Sur con destino a los EE. UU. (GAO, 1993), lo cual afianzó la relación entre los cárteles colombianos y mexicanos, aunque en sus orígenes se presentaba una relación subordinada de las organizaciones mexicanas hacia las organizaciones colombianas.

Desde los años ochenta, la FAM participa en operaciones de "alto impacto" enfocadas a la erradicación de cultivos ilícitos de amapola y marihuana. No obstante, en los últimos años esas actividades se han extendido a la vigilancia aérea, marítima y terrestre para hacer frente al tráfico de narcóticos. Durante la presidencia de Felipe Calderón (2006-12), según se estableció en la Directiva para el Combate Integral del Narcotráfico 200712 , aeronaves y helicópteros fueron desplegados y asignados directamente a las zonas regionales para hacer frente al narcotráfico. De hecho, la FAM actualmente tiene como principal misión el "combate frontal al narcotráfico y otras expresiones del crimen organizado". Entre los objetivos establecidos en la citada Directiva están los siguientes: I) hacer más eficiente la operatividad del Ejército y Fuerza Aérea Mexicanos, aumentando a seis horas de vuelo de adiestramiento mensual por piloto aviador; II) garantizar la Defensa Nacional y respaldar la política exterior del Estado Mexicano, incrementando en un 30\% las actividades de cobertura, protección y vigilancia del espacio aéreo nacional, y III) apoyar las políticas en materia de seguridad interior, en un marco de respeto al Estado de Derecho, disminuyendo el área de siembra de enervantes en un 70\% y el combate a la delincuencia organizada en áreas específicas del país.

Entre las prioridades que la SEDENA y la FAM han seńalado está el fortalecimiento del Sistema de Vigilancia Aérea de México (SIVA). Sin embargo, como se muestra a continuación aún son varios los retos que la FAM enfrenta al respecto.

\section{El Sistema de Vigilancia Aérea de México (SIVA)}

Las fuerzas armadas mexicanas se componen de dos instituciones independientes: la Secretaría de la Defensa Nacional (SEDENA), la cual incluye al Ejército y la FAM, y la Secretaría de Marina (SEMAR), comprendida por la Armada, la cual incluye a su vez a la flota, la fuerza aérea naval y el cuerpo de infantería de marina. Sus estructuras internas pueden verse en las figuras 5.3 y 5.4. El Ejecutivo es el comandante en jefe y tiene control directo sobre las fuerzas armadas a través de la SEDENA y la SEMAR (Guevara, 2011). 


\section{Figura 5.3}

Organigrama de la Secretaría de la Defensa Nacional de México

SECRETARÍA DE LA
DEFENSA NACIONAL

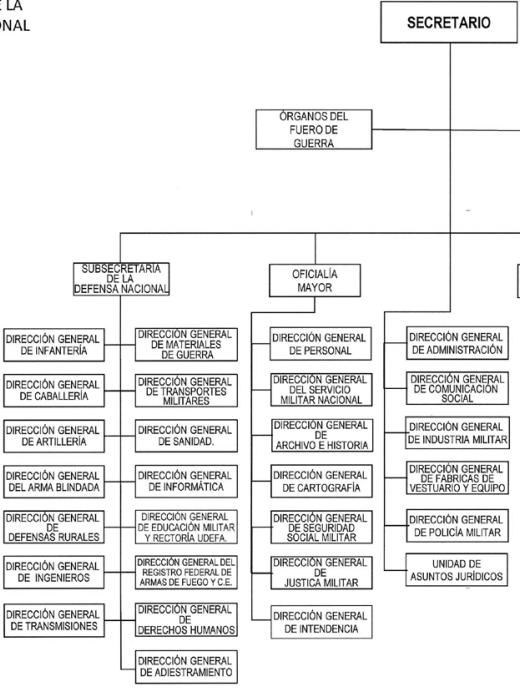

\begin{tabular}{c}
\hline ESTADOMAYOR DELA \\
DEFENSA NACIONAL \\
\hline
\end{tabular}

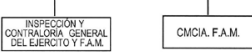

FUENTE: MANUAL DE ORGANIZGCIÓN

GENERAL. DE LA SECRETARIA DE LA

DEFENSA NACIOAAL, PUBLLCADO EN EL

DIARIO OFICIAL DEL 4 JUL. 2017.

Nota: Organigrama de la Secretaría de la Defensa Nacional (SEDENA, 2020b).

\section{Figura 5.4}

Organigrama de la Comandancia de la Fuerza Aérea Mexicana.



Nota: Organigrama de la Secretaría de la Defensa Nacional (SEDENA, 2020b). 
En lo que respecta a la vigilancia del espacio aéreo mexicano durante la administración federal del presidente Vicente Fox (2000-06), específicamente en el año 2004, se creó el Centro de Mando y Control del SIVA con la finalidad de mejorar las capacidades de vigilancia y control del espacio aéreo mexicano, con especial énfasis en la lucha al tráfico aéreo ilegal de narcóticos. Sin embargo, desde la década de 1990 había un interés por parte del gobierno de EE. UU. en sobrevolar espacio aéreo mexicano para operaciones de interdicción aérea.

Desde mediados de la década de los años ochenta, las señales de desgaste de la Unión Soviética, tanto en su política interna (expresada en la implementación de reformas como la Glasnot y la Perestroika) como en su poderío militar en el exterior (v.g. Afganistán) evidenciaban la cercanía del fin de la Guerra Fría. Ante la debacle de la "amenaza rusa”, EE. UU. comenzó a poner mayor atención en la construcción ideológica y la justificación para hacer frente a la "nueva amenaza" que enfrentaban: las drogas ilegales. Amenaza que en realidad no era tan nueva y que en algunos momentos fue auspiciada y utilizada para los fines estadounidenses, tal y como lo demostró el caso Irán-Contras y la presunta colaboración entre la Central de Inteligencia Americana y el Cártel de Guadalajara ${ }^{53}$ o el respaldo que recibió Manuel Noriega, antes de la invasión a Panamá y su encarcelamiento acusado de narcotráfico.

En mayo de 1988, aún en un contexto de Guerra Fría, el presidente Ronald Reagan declaró 'emergencia nacional' la guerra contra el narcotráfico calificándola como el enemigo público número uno de los Estados Unidos ${ }^{54}$. Como parte de esa declaración la administración Reagan lanzó una campaña de advertencia a la sociedad estadounidense en la que se afirmaba que la competitividad de la economía de ese país se encontraba amenazada por una nueva epidemia en el consumo de drogas (Valdés, 2013).

Para 1990, agencias y fuerzas militares estadounidenses comenzaron a impulsar la creación de una fuerza conjunta para operaciones de interdicción aérea en la frontera México-EE. UU. e incluso buscaban ir más allá y planteaban la necesidad de una fuerza regional de interdicción de drogas en otros países latinoamericanos. No obstante, ellos reconocían que tanto en México

53 Semana. (20 de agosto de 1990). Narcotráfico y CIA. SEMANA. Recuperado de https://www. semana.com/mundo/articulo/narcotrafico-cia/13757-3

54 El País. (20 de mayo de 1988). Reagan declara la lucha contra la droga "emergencia nacional". El Pais. Recuperado de https://elpais.com/diario/1988/05/20/portada/580082404_850215. html 
como en otros países se podrían "encontrar obstáculos significativos, incluyendo problemas relacionados con la soberanía y con la coordinación que se requiere antes y durante una operación de interdicción" (GAO, 1993).

Según se establece en un documento titulado Drug Control: Revised Drug Interdiction Approach is Needed in México (1993), generado por la General Accounting Office, en 1990 EE. UU. y México crearon el programa: Fuerza de Respuesta de la Frontera del Norte ${ }^{55}$ para interceptar a los narcotraficantes en el aire y eliminar el uso del norte de México como área de preparación para los envíos de cocaína con destino a los Estados Unidos. Desde ese momento hasta la fecha del reporte (1993) EE. UU. había proporcionado \$38.9 millones en asistencia directa para el programa. Según se señala en el mismo documento, entre los objetivos del programa estaban los siguientes: proporcionar en arrendamiento 21 helicópteros $\mathrm{UH}_{1} \mathrm{H}^{56}$ para los equipos de interdicción; crear siete bases de operaciones móviles; detectar aeronaves cargadas de drogas, interceptar las aeronaves mientras aterrizan en México, arrestar a los traficantes, incautar aeronaves y narcóticos, y realizar investigaciones de seguimiento para recolectar evidencia que pueda usarse para desmantelar organizaciones criminales (GAO, 1993). Sin embargo, este programa piloto no fructificó como se esperaba, pues se enfrentó a factores como las reticencias y la cautela por parte del gobierno de México y la sensibilidad respecto al tema de la soberanía. En lo que respecta a los EE. UU. la aprobación de la entrega de helicópteros se enfrentó a dificultades debido al conflicto con Irak.

55 Estados Unidos y México establecieron conjuntamente el programa Fuerza Fronteriza de Respuesta de la Frontera Norte (NBRF, por sus siglas en inglés) en 1990. Este programa implica el uso de activos de radar de EE. UU. para detectar y monitorear aviones sospechosos provenientes de Colombia, rastrear aviones sospechosos con aviones especialmente equipados desde el momento en que ingresan a espacio aéreo mexicano hasta que aterrizan, arrestan a los traficantes y se apoderan de sus cargas, y realizan investigaciones de seguimiento para recolectar evidencia que pueda usarse para desmantelar los grupos de traficantes. El Departamento de Estado y el Departamento de Defensa (DOD), la DEA y el Servicio de Aduanas de EE. UU. trabajan con la Procuraduría General de la República para lograr estos objetivos (GAO, 1993).

56 El Departamento de Estado y el Departamento de Defensa determinaron que Estados Unidos podría proporcionar 21 helicópteros UH-1H del Ejército de los EE. UU. al gobierno de México a través de la sección 606 (a) (2) de la Ley de Asistencia Extranjera. La Embajada de los Estados Unidos propuso que Estados Unidos arrendara los 21 Helicópteros UH-1H a México, además de proporcionar los repuestos necesarios y los servicios y equipos de apoyo relacionados. El presidente Bush aprobó esta solicitud en julio de 1990.Los helicópteros UH$1 \mathrm{H}$ se entregaron en dos envíos. El primer envío de 9 helicópteros se entregó en noviembre de 1990, y el segundo envío de 12 helicópteros se entregó en marzo de 1992 (GAO, 1993). 
La implementación de este programa tuvo algunos éxitos iniciales ${ }^{57}$ en suprimir los vuelos de aeronaves ilegales en la frontera norte de México; no obstante, entre las externalidades generadas estuvo la rápida capacidad de adaptación de los cárteles del narcotráfico, los cuales buscaron nuevas rutas hacia los EE. UU. desde el centro y el sur de México, y Guatemala. Un detallado recuento de la historia del surgimiento de Vigilancia Aérea en México es el realizado por Iñigo Guevara, quien documenta que:

En julio de 1990 una misión especial de EE. UU. informó al presidente Carlos Salinas sobre las intenciones de EE. UU. de mejorar la interdicción en el Caribe, América Central y el Pacífico Oriental y ofreció proporcionar helicópteros y continuar compartiendo información con México el 9 de julio de 1990. La misión también solicitó permiso para sobrevolar territorio mexicano con vigilancia Lockheed P-3 Orion aviones para que puedan mejorar la detección de las rutas de tráfico de narcóticos utilizadas para ingresar a los Estados Unidos. El plan de los Estados Unidos era tener tripulaciones aéreas estadounidenses y mexicanas conjuntas para el P-3 Oriones. La oferta fue rechazada por el presidente Salinas de Gortari quien respondió que los Oriones P-3 tendrían que ser entregados a la FAM si iban a operar sobre México y que uno o dos observadores estadounidenses tendrían permitido participar como parte de la tripulación. El gobierno mexicano ofreció arrendar uno o varios P-3 y anunció que tendría tripulaciones listas para ser entrenadas dentro de las 24 horas de aceptación. El rechazo fue un claro manifiesto de que la cooperación con los Estados Unidos todavía estaba limitado por las sensibilidades de la soberanía de México. (2016, p. 34)

Aunque esta sensibilidad se redujo considerablemente en las últimas dos décadas, sobre todo con el Plan Mérida y la cercanía que Calderón mantuvo con agencias federales estadounidenses, la presencia de agencias estadounidenses aún es vista con recelo por ciertos sectores de la clase política y de la sociedad mexicana que apelan a mantener la soberanía en asuntos internos.

57 La incautación más exitosa ocurrió el 14 de octubre de 1990, el día en que el programa comenzó a funcionar. En esta fecha el programa Fuerza Fronteriza de Respuesta de la Frontera Norte respondió a la información desarrollada por los activos de vigilancia de los EE. UU. e interceptó a siete aviones procedentes de Colombia cuando aterrizaron en un camino de tierra en el centro norte de México. Cinco de los aviones quedaron atrapados en el suelo y fueron incautados o destruidos. Esta operación también resultó en la incautación de más de nueve y media toneladas métricas de cocaína y el arresto de varios pilotos colombianos (GAO, 1993). 
Durante la administración de Ernesto Zedillo (1994-2000) se ordenó a la FAM que interceptara vuelos ilegales y rastreara vuelos que estuvieran realizando operaciones de contrabando de narcóticos. Sin embargo, México no adoptó una ley de derribo por lo que sólo se podían interceptar e intimidar vuelos ilegales para aterrizar o rastrearlos y coordinarlos con los activos terrestres para interceptarlos una vez que habían aterrizado (Guevara, 2016). Desde los años noventa era evidente que el espacio aéreo de México era ampliamente vulnerable al tráfico aéreo ilegal y, al mismo tiempo, que la FAM no disponía de las herramientas legales, ni de las capacidades humanas y materiales para vigilar el espacio aéreo en contra de incursiones de aeronaves sospechosas, ilegales o ilícitas.

En octubre de 1998, representantes del Ministerio del Interior de México (SEGOB), el Centro de Investigación de Seguridad (CISEN) y la Oficina de Asuntos Especiales de la Embajada de México en Washington D.C. presentaron ante la SEDENA un proyecto para el establecimiento de una red de vigilancia del espacio aéreo para fortalecer la estrategia del gobierno en contra de vuelos ilegales, en especial para contrarrestar el tráfico de narcóticos (Guevara, 2016). A partir de entonces se empezaron a analizar los sistemas de vigilancia aérea existentes en diverso países de la región.

La SEDENA tuvo entre sus referentes iniciales al Sistema Integrado de Vigilancia Amazónica de Brasil (SIVAM). Esa influencia se tradujo en la adquisición de un Embraer brasileño EMB-145AEW \& $\mathrm{C}$ y dos aviones de patrulla marítima EMB-145MP en 2001 (Guevara, 2016). De hecho, esas aeronaves son las plataformas aéreas de las que actualmente dispone la FAM como parte del SIVA. Según información de la SEDENA el SIVA es:

Un organismo técnico-operativo que administra los medios de detección, enlace e intercepción aéreos y terrestres pertenecientes a la SEDENA, encaminados a la protección y vigilancia del espacio aéreo mexicano. Tiene como objetivo primordial, garantizar la soberanía nacional mediante el planeamiento, organización, control y supervisión de operaciones aéreas y terrestres orientadas a prevenir amenazas a la seguridad nacional, como es el tráfico de drogas en sus modalidades aérea y marítima, entre otras. Lo anterior, a través del empleo de medios de detección terrestres y aéreos, complementados con los demás medios aéreos, terrestres y anfibios desplegados en el territorio del país, que contribuyen a generar y difundir en tiempo real, la información de valor militar que contribuya al seguimiento 
de los blancos aéreos y su posterior interceptación y aseguramiento. Este sistema dispone del apoyo de otras instituciones nacionales y extranjeras, mediante el intercambio de información respecto al seguimiento de blancos aéreos sospechosos o ilícitos, provenientes de otros países y fuera del alcance de nuestros medios de detección, lo que representa un valioso aspecto para la adecuada toma de decisiones, una vez que la amenaza ingrese a territorio nacional. (2007)

Para cumplir con su misión, el SIVA está organizado con cinco componentes como se puede observar en detalle en la tabla 5.3:

\section{Tabla 5.3}

Componentes del Centro de Mando y Control del Sistema Integral de Vigilancia Aérea

\begin{tabular}{|l|l|}
\hline \multicolumn{1}{|c|}{$\begin{array}{c}\text { Componentes del } \\
\text { SIVA }\end{array}$} & \multicolumn{1}{c|}{ Funciones } \\
\hline $\begin{array}{l}\text { 1. De mando } \\
\text { y control }\end{array}$ & $\begin{array}{l}\text { Lo constituye el Centro de Mando y Control del SIVA, } \\
\text { que coordina los medios de enlace e información para el } \\
\text { planeamiento y supervisión de las misiones de vigilancia } \\
\text { aérea. }\end{array}$ \\
\hline 2. De detección & $\begin{array}{l}\text { Constituido por radares terrestres y radares aerotranspor- } \\
\text { tados instalados en las plataformas aéreas de la Fuerza Aé- } \\
\text { rea Mexicana. }\end{array}$ \\
\hline 3. De intercepción & $\begin{array}{l}\text { Se integra con aviones y helicópteros de la Fuerza Aérea } \\
\text { Mexicana, así como las tropas terrestres y anfibias del } \\
\text { Ejército desplegadas estratégicamente en todo el territorio } \\
\text { nacional. }\end{array}$ \\
\hline 4. De adiestramiento & $\begin{array}{l}\text { Constituido por un Centro de Simulación y Adiestra- } \\
\text { miento, cuya función consiste en crear escenarios de ope- } \\
\text { ración a todo el personal que participa en el seguimiento } \\
\text { de blancos ilícitos. }\end{array}$ \\
\hline 5. Infraestructura \\
de apoyo & $\begin{array}{l}\text { Integrado con tres hangares de alta seguridad, manteni- } \\
\text { miento y apoyo a las operaciones de las plataformas de } \\
\text { vigilancia aérea, sistemas de comunicaciones de la SEDE- } \\
\text { NA e información radar de agencias gubernamentales na- } \\
\text { cionales y extranjeras. }\end{array}$ \\
\hline
\end{tabular}

Nota: Elaboración propia con información de la Secretaría de la Defensa Nacional, 2007a. 
Como se ha expuesto, la FAM ha cobrado un papel de gran relevancia en las actividades de combate al narcotráfico y combate al crimen organizado. Como parte del proceso de modernización y mejora de capacidades se adquirieron 80 aeronaves y helicópteros, ocho de los cuales fueron proporcionados por los EE. UU. a través de la Iniciativa Mérida (Guevara, 2011). Entre 2007-12 la SEDENA amplió la vigilancia del espacio aéreo mediante la adquisición de un sistema de radares y la compra de sistemas aéreos no tripulados, helicópteros B-412, EC-275 Cougar, aviones CASA C-295M, C-27J Spartan y aviones T-6c Texano ${ }^{58}$.

En 2008 también se adquirieron Vehículos Aéreos No Tripulados ${ }^{59}$, comúnmente conocidos como drones, los cuales comenzaron a operar en abril del 2009. Se dispone de sistemas Elbit Hermes 450 (Guevara, 2011) y en mayo de 2009, la FAM creó un Escuadrón de Sistemas Aéreos No Tripulados (ESANT). Este grupo fue transferido al Centro de Mando y Control del SIVA de la SEDENA, en junio de 2010 (Guevara, 2015).

Como parte de esta investigación se hizo una solicitud de información (folio No. 0000700266319) a la SEDENA, sobre "el número de drones de los que dispone actualmente la Secretaría de la Defensa Nacional para tareas de vigilancia aérea", a lo que se respondió que "la cantidad de aeronaves pilotadas a distancia (RPAS) con que cuenta la SEDENA, se encuentra clasificada como reservada" por motivos de seguridad nacional. Sin embargo, se indicó que se cuenta con las siguientes aeronaves pilotadas a distancia: Hermes 450, S-4 Ehécatl y Baalam S-45.

En el libro blanco Fortalecimiento de la Fuerza Aérea Mexicana (20122018) se señala que en el 2016 se adquirieron tres sistemas aéreos no tripulados a la empresa Hydra Technologies de México con un costo de \$309.933.281,25 pesos mexicanos. Dicha empresa produce el dron denominado dron S4 Ehécat ${ }^{60}$. De acuerdo con documentos oficiales de la SEDENA,

58 Castillo, G. y Murillo, E. (2 de febrero de 2020). La FAM consolidará este año la vigilancia del espacio aéreo nacional. La Jornada. Recuperado de https://www.jornada.com. $\mathrm{mx} / 2020 / 02 / 02 /$ politica/007n1 pol

59 Dependencias militares también le entraron al juego de los “drones". En julio de 2008, la Secretaría de la Defensa Nacional (SEDENA) firmó un contrato de 25 millones de dólares con Elbit Systems por la compra de un UAS Hermes 450 y tres mini UAS Skylark I. El Hermes 450, de tamaño mediano, tiene un alcance de 200 kilómetros y 18 horas de duración, mientras que el Skylark I, un UAS que se lanza con la mano, tiene un alcance de 15 kilómetros y 3 horas de duración (Guevara, 2015).

60 Guevara, I. (11 de julio de 2015). Los drones de México: quién los utiliza y por qué. Animal Politico. Recuperado de https://www.animalpolitico.com/2015/07/los-drones-de-mexico- 
Hydra Technologies donó un S4 Ehécatl y un UAS G1 Guerrero en julio de 2012. Estos "drones" fueron integrados al ESANT para operar junto con el Hermes 450. La SEDENA utiliza las aeronaves no tripuladas para labores de inteligencia contra organizaciones criminales, para patrulla en zonas fronterizas y para la vigilancia de instalaciones estratégicas (Guevara, 2015).

Varias de las fuentes consultadas para esta investigación coinciden en indicar que la cobertura que tiene la FAM del espacio aéreo mexicano ha sido y continúa siendo bastante limitada, lo cual se presenta como una ventana de vulnerabilidad para la seguridad nacional de México. De hecho, esto ha sido reconocido en diversos documentos emanados de la Secretaría de la Defensa Nacional. Concretamente se ha llamado la atención sobre la necesidad de incrementar la cobertura de radar, ya que actualmente es de alrededor de $32 \%{ }^{61}$. También se ha planteado la necesidad de actualizar y mejorar las capacidades del SIVA, cuestión que a la fecha no ha sucedido. Es decir, en el período 2007-19 la cobertura del espacio aéreo nacional no se incrementó ${ }^{62}$, esto pese a que era uno de los objetivos prioritarios establecidos por la SEDENA.

Para reducir esta clara vulnerabilidad, como se señaló anteriormente, a principios del siglo XXI se adquirieron aeronaves Embraer EMB-145 RS\&MP y Embraer 145MCSA-AEWC de alerta temprana. Estas aeronaves son empleadas para la vigilancia aérea y estratégica contra incursiones ilegales y en seguimiento a vuelos ilegales ${ }^{63}$; sin embargo, requieren modernizarse y sumar otras plataformas aéreas para mejorar el control del espacio aéreo mexicano.

quien-los-utiliza-y-por-que/

61 Otras fuentes señalan que "mediante el empleo de las 6 plataformas aéreas, se logró un promedio de cobertura radar del 48 por ciento del territorio nacional, enfocando esta vigilancia hacia aquellas áreas con mayor incidencia en el tráfico ilícito de drogas vía aérea, principalmente en las regiones sureste y noroeste del país, logrando con ello, un efecto disuasivo en la realización de estas actividades ilícitas y con lo cual ha decrecido sensiblemente la ocurrencia de aeronaves sospechosas procedentes de Centro y Sudamérica” (SEDENA, 2007a).

62 SEDENA (2020a). Primer Informe de Labores 2018-2019. SEDENA. Recuperado de http:// www.sedena.gob.mx/pdf/informes/primer_informe_labores.pdf

63 Medellín, A. (1 de junio de 2018). Los Embraer 145 de la Fuerza Aérea Mexicana en la última etapa de overhaul. Defensa.com Recuperado de https://www.defensa.com/mexico/embraer-145-fuerza-aerea-mexicana-ultima-etapa-overhaul [Consultada el 26 de noviembre de 2019]. 


\section{Avances y Retos que Enfrenta el Proceso de Moderniza- ción de la Fuerza Aérea Mexicana}

Según se establece en el Libro Blanco de Fortalecimiento de la FAM (LB03), entre 2012-18, se adquirieron 143 aeronaves nuevas (102 aviones y 41 helicópteros) y tres sistemas aéreos no tripulados equipados con tecnología de vanguardia (SEDENA, 2018). Además, según lo señalado por el Informe de Rendición de Cuentas de Conclusión de la Administración 2012-18 (SEDENA, 2018), durante la administración del presidente Enrique Peña Nieto se ejecutaron diversas acciones relacionadas con la FAM, entre las que se relacionan con esta investigación se pueden resaltar las siguientes nueve. Primero, se mantuvo un porcentaje operacional del total de aeronaves de la FAM superior al $80 \%$, manteniendo un promedio mensual de 6 horas y 30 minutos de vuelo por piloto aviador (SEDENA, 2018, p. 4). Con lo anterior se cumplió con la meta que se había establecido desde 2007. Segundo, 1556 elementos de la FAM, realizaron adiestramientos recurrentes y 3816 ingresaron a los diferentes plantes de educación militar de la Fuerza Aérea. Personal de la FAM realizó 589 cursos en el extranjero (SEDENA, 2018, p. 4). Tercero, se realizaron 11 reuniones para el intercambio de experiencias y seminarios con los organismos de inteligencia de las Fuerzas Armadas de Colombia y Nicaragua (SEDENA, 2018, p. 7). Cuarto, se suscribieron cuatro Memorandos en materia de intercambio de información con los países de Colombia, Guatemala, Nicaragua y el Reino de España (SEDENA, 2018, p. 7). Quinto, personal de las diferentes especialidades de la FAM realizaron 111 cursos en el extranjero (SEDENA, 2018: 16), incluida Colombia. Sexto, para incrementar y renovar la infraestructura de la FAM se destinaron un total de $\$ 16.074$ millones de pesos mexicanos, correspondientes al presupuesto de la SEDENA y $\$ 3214$ millones de pesos mexicanos, provenientes de Arrendamientos Financieros autorizados por la Secretaría de Hacienda y Crédito Público (SHCP). El presupuesto señalado permitió implementar la adquisición de 100 aeronaves de ala fija, 41 de ala rotativa, radares, equipo meteorológico, entre otros equipos (SEDENA, 2018, p. 29). Séptimo, se hizo mantenimiento y reparación de componentes del Sistema de Radar ERINEYE, incluyendo la administración de datos C-2 instalados en la plataforma de vigilancia aérea EMB-145 Mat. $4101^{64}$ (SEDENA, 2018, p. 37). Octavo, se realizaron 374, 714:09 horas

64 La FAM cuenta con tres plataformas aéreas Embraer 145 MCSA-AEWC adquiridas en 2003, durante la presidencia de Vicente Fox y equipados con la versión P99 que posee un radar 
de vuelo, para garantizar la vigilancia del espacio aéreo nacional (SEDENA, 2018 , p. 31). Noveno, se obtuvo un $70 \%$ de avance en la reestructuración de los Centros de Mando y Control del SIVA ${ }^{65}$ (SEDENA, 2018, p. 31).

En cuanto a los aspectos que quedaron pendientes, según lo que se señala en el Programa Sectorial de Defensa Nacional 2013-2018, se puede destacar que se había establecido el objetivo de incrementar la cobertura del espacio aéreo mexicano a un $72 \%$; pero, se mantuvo la cobertura en un 32\%, debido a que únicamente se logró adquirir un Centro de Mando y Control, tres sistemas aéreos no tripulados y la asignación de 12 aeronaves de ala fija para el SIVA para su seguimiento e intercepción.

En lo que se refiere a los radares al servicio de la SEDENA, desde 2007, en el marco de un proyecto para modernizar las capacidades de detección de SIVA, se identificó que los radares aéreos eran efectivos, pero los radares terrestres estaban significativamente desactualizados. En el documento Directiva Integral para el Combate al Narcotráfico se describe que las capacidades de detección y seguimiento de los tres radares terrestres Westinghouse TPS70 3-D (Guevara, 2011), que habían estado en uso desde enero de 1989, no estaban operando al $100 \%$. El documento mencionado establece que los radares sólo funcionan en modo secundario, pudiendo proporcionar datos para los controladores de tránsito aéreo pero ineficaz detectar vuelos de baja altura. Después de considerar varios tipos de radares, la FAM seleccionó el AN / TPS-78 y realizó un pedido de USD 118 millones en 2010, los cuales comenzaron a ser entregados en 2011 (Guevara, 2016, pp. 45-46).

Además, los componentes del SIVA tienen más de una década de servicio, por lo que se requiere su modernización y renovación para aumentar la cobertura del espacio aéreo nacional. También quedó pendiente la actualización de los sensores de tres plataformas aéreas; la adquisición de una plataforma de vigilancia aérea y alerta temprana, cinco radares de largo alcance y tres sistemas aerotransportados (plataformas) [SEDENA, 2018, p. 33]. La SEDENA señaló que este objetivo no se cumplió debido a insuficiencia presupuestaria (SEDENA, 2018, p. 48).

sueco Ericsson Erieye (Medellín, 2018).

65 En el ejercicio fiscal 2015 se gastaron $\$ 633,705,063$ millones de pesos para la instalación y operación de un nuevo Centro de Mando y Control del Sistema de Vigilancia Aérea, fase 1 (diseño y desarrollo de la arquitectura del sistema, capacitación técnica y operacional); implementación de un Sistema de Enlace de Datos Táctico para el Sistema Integral de Vigilancia Aérea (SIVA) [SEDENA, 2018, pp. 36-37]. 
Otro objetivo era incrementar en un 50\% la movilidad estratégica (172 aeronaves y tres Sistemas No Tripulados). Se logró este objetivo en un $40.98 \%$, ya que se adquirieron 141 aeronaves (100 aviones y 41 helicópteros) y tres Sistemas No Tripulados, quedando pendiente la adquisición de 31 aeronaves (SEDENA, 2018, p. 34).

Si bien se cumplió con el objetivo de incrementar las horas de vuelo este aumentó en 47\% de las horas de vuelo, entre 2012-18, ha incidido en el desgaste de aeronaves y material aéreo, lo cual derivó en que se procediera a tramitar la baja de 66 aeronaves con más de dos décadas de uso, cuyo mantenimiento no era redituable, ni garantizaban condiciones de seguridad (C.G. Fuerza Aérea Mexicana, 2018).

Para el período comprendido entre 2013-30 se tenía proyectado un proceso, comprendido en tres fases, con el objetivo de modernizar las aeronaves de la FAM. La intención principal era sustituir y renovar gradualmente el equipo aéreo más que incrementarlo. Este proceso de modernización se proyectó como se puede observar en la tabla 5.4 .

\section{Tabla 5.4}

Proceso de modernización de las aeronaves de la Fuerza Aérea Mexicana 2013-30

\begin{tabular}{|c|c|c|}
\hline Primera fase 2013-18 & Segunda fase 2019-24 & Tercera fase 2025-30 \\
\hline 24 helicópteros UH-60. & 24 helicópteros UH-60. & 24 aviones interceptores \\
24 helicópteros MI-17. & 24 helicópteros MI-17. & 3 aviones K.A. 350 con \\
36 helicópteros B-407AH. & 12 helicópteros B-407AH. & sensores de vigilancia \\
48 aviones T-6C+. & 30 aviones T-6C+. & 3 EMB-145 \\
1 avión Grunmman & 7 aviones C-235. & con radar aéreo. \\
Gulfstream. & 3 aviones C-130J. & \\
8 aviones K.A. 350 & 4 aviones B737-700. & \\
ambulancia/tpte. pnal./I.S.R. & & \\
\hline
\end{tabular}

Nota: Comando General de la Fuerza Aérea Mexicana. En: Ricardo Sodi (coordinador) [2018]. La Fuerza Aérea en la Defensa del Estado. Editorial Porrúa. México.

Aunque, desde 1929, las Fuerzas Armadas mexicanas han mantenido un alto grado de institucionalidad hacia el Estado mexicano, independientemente de quien ocupe el Ejecutivo Federal ${ }^{66}$, esto no evita que estas se ven afecta-

66 En 1940, durante la presidencia del general Manuel Ávila Camacho, el sector militar ligado al Partido Revolucionario Mexicano (posteriormente PRI) desapareció definitivamente. Fue una prueba simbólica de la profesionalización alcanzada por el ejército revolucionario y de su 
das por los vaivenes y externalidades del cambio político que se ha presentado en México desde el año 2000, cuando por primera vez en 71 años el Partido Revolucionario Institucional (PRI) perdió la presidencia frente al candidato del Partido Acción Nacional (PAN), partido que logró mantener la presidencia de México entre 2000-12, para luego perderla nuevamente frente al PRI entre 2012-18.

Ejemplo de la influencia que tuvo el cambio político sobre las Fuerzas Armadas se hizo evidente durante el período del presidente Felipe Calderón (2006-12), y en un contexto en el que el presidente declaró una guerra en contra del crimen organizado, cuando las Fuerzas Armadas mexicanas se vieron insertas en un contexto que abrió una ventana de oportunidad que les permitió mejorar sus condiciones laborales y salariales. $\mathrm{Al}$ mismo tiempo, éstas iniciaron un proceso de adaptación, transformación y modernización, sobre todo para responder a los retos que la inseguridad y la violencia generada por el crimen organizado han producido en México en las últimas dos décadas. Aunque en el 2012 el PRI regresó a la presidencia con Enrique Peńa Nieto se mantuvo el respaldo al proceso de modernización de las Fuerzas Armadas que se venía gestando desde la administración anterior.

En las elecciones presidenciales de 2018 resultó electo Andrés Manuel López Obrador también conocido como AMLO, fundador y candidato del partido Movimiento de Regeneración Nacional (MORENA), quien ha hecho del combate a la corrupción y de la austeridad de la administración federal dos de sus principales ejes de gobierno. Aunque AMLO ha mantenido una inesperada cercanía con las Fuerzas Armadas, la política de austeridad podría afectar el proceso de modernización de la FAM proyectado hacia el 2030.

Tener en cuenta lo anterior resulta pertinente, dado que, entre los recortes administrativos o las políticas de austeridad se han puesto a la venta aeronaves adscritas a distintas dependencias federales, incluidas la SEDENA y la SEMAR. De acuerdo con la información disponible en la página web del Gobierno de México "catálogo de aeronaves susceptibles de venta”, publicada el 22 de abril de 2019, la venta de aeronaves se sustenta en lo siguiente:

Atendiendo a los principios de responsabilidad y uso eficiente de los recursos públicos, el Presidente de la República anunció la enajenación del denominado avión presidencial (TP01, José María Morelos y Pavón) e

subordinación institucional al jefe del poder ejecutivo, una tendencia que habría de volverse realidad política permanente a partir de 1946, con la elección del primer presidente civil. Tradición que se ha mantenido ininterrumpida hasta la actualidad. (Aguilar \& Meyer, 1991). 
instruyó identificar todas aquellas aeronaves que cumplieran con dos criterios básicos: 1) Aeronaves cuyo uso estuviera dedicado a la transportación ejecutiva de servidores públicos, que no cumplieran funciones directamente relacionadas con los programas y acciones de las dependencias, y que no tuvieran una función clara en beneficio de la ciudadanía. 2) Aeronaves que por sus características no estuvieran en servicio y generen gastos derivados del resguardo, mantenimiento y operación ${ }^{67}$.

De tal manera, con la llegada de la administración federal (2018-24) se vislumbra un escenario complejo para poder continuar con el proceso de sustitución y modernización de aeronaves y del SIVA emprendido por la FAM en 2013. Cabe aclarar que, el problema no es la política de austeridad sino que ésta no responda a criterios de racionalidad y eficiencia en el cumplimiento de los objetivos planteados para mejorar la capacidad de los recursos humanos y materiales de la FAM y salvaguardar al Estado y sociedad mexicanos de las amenazas externas e internas, en específico la vulnerabilidad que desde hace décadas presenta el espacio aéreo mexicano y, específicamente, la amenaza que presenta el tráfico aéreo ilegal de narcóticos.

\section{El Tráfico Aéreo Ilegal de Narcóticos como Amenaza el Espacio Aéreo Mexicano}

En México se tiene la cobertura de radares civiles, pero estos están enfocados únicamente a ciertas elevaciones que cubren las rutas en las que opera la aviación comercial. Sin embargo, no se cuenta con una cobertura aérea completa ni con la cobertura de radares civiles, ni tampoco con la de radares militares (González, 2018). De hecho, como ya se ha mencionado, la SEDENA ha reconocido que sólo se dispone de una cobertura de alrededor del $32 \%$ del espacio aéreo mexicano.

Esa vulnerabilidad ha sido aprovechada por los narcotraficantes, destacando el caso de Amado Carrillo Fuentes, cuyo alias "el señor de los cielos" se debía a los grandes embarques de narcóticos que trasladaba por vía aérea con aviones LearJet e incluso con Boeing 727 desde México hacia Estados

67 Gobierno de México. (22 de abril de 2019). Catálogo de aeronaves susceptible de venta. Disponible en: https:/www.gob.mx/banobras/documentos/catalogo-de-aeronaves-susceptibles-de-venta 
Unidos. El cártel de Juárez, organización de Amado Carrillo, que, según el ex tesorero del grupo de Cali, Guillermo Palomari, había iniciado negocios con Miguel Rodríguez Orejuela, se colocó a la cabeza de la estructura oligopólica en el tráfico de cocaína. El trato consistía en la mitad para el cártel de Cali y la otra para el cártel de Juárez liderado por Carrillo, quien se comprometía a pasar la droga hacia EE. UU. (Astorga, 2016). La historia en torno a Amado Carrillo Fuentes es ilustrativa de las dimensiones que adquirió el tráfico aéreo ilegal de narcóticos a través del espacio aéreo mexicano ${ }^{68}$.

En México ocurren innumerables ingresos aéreos ilícitos a territorio nacional por parte de aeronaves que transportan estupefacientes. Aunque en algún momento el Estado mexicano tuvo control del espacio aéreo, con los años este disminuyó (González, 2018). Es el caso de la frontera sur de México, que desde hace décadas es una de las principales puertas de acceso para el tráfico aéreo y marítimo ilegal proveniente de Sudamérica y Centroamérica. Así lo ilustra la notoria vulnerabilidad aérea que se presenta en la frontera entre el estado de Quintana Roo (México) y el norte de Belice y Guatemala.

Esta zona se ha convertido en un espacio propicio para los vuelos ilegales de aeronaves provenientes de Colombia, Venezuela ${ }^{69}$ y Bolivia. Desde hace décadas organizaciones mexicanas y colombianas utilizan el territorio de Belice, su espacio aéreo, terrestre y marítimo, para transportar cocaína hacia México y luego introducirla a los Estados Unidos. En el caso de Guatemala

68 "Transportar estupefacientes por vía aérea no fue un invento de Carrillo, pues de los años cincuenta lo hacían lo sinaloenses; lo que aportó fue la magnitud y la eficacia que utilizó. Su flota de aviones pequeños, Lear Jet fue incrementada cuando salió del reclusorio sur en junio de 1990; incluso llegó a experimentar con aviones más grandes. En San Diego compró un jet Boeing 727 usado, en 300 mil dólares para transportar cinco toneladas de cocaína en un viaje; después adquirió otros dos aviones del mismo modelo, pero el experimento no funcionó por lo viejo de las aeronaves - con frecuencia tenían que aterrizar de emergencia- y los problemas de mantenimiento correspondientes, por lo que retomaron los aviones pequeños que transportaban media tonelada de cocaína por viaje. Algunas estimaciones de autoridades estadounidenses señalan que la organización de Juárez transportaba por lo menos 60 toneladas de cocaína al año, lo que significaba 120 vuelos, uno cada tercer día. La droga se la llevaban las organizaciones colombianas a la península de Yucatán (vía algunos países centroamericanos desde donde la transportaban por vía marítima a Chetumal, Cancún o alguna playa de la Riviera Maya); desde allí la trasladaban a Guadalajara, Torreón y Hermosillo por vía aérea donde tenían almacenes de depósito; luego la acercaban hasta Chihuahua, a un rancho de su propiedad cercano a la frontera de Estados Unidos". (Valdés, 2013, p. 243).

69 Patón, N., Gallón, N., y Castrillón, D. (17 de abril de 2019). La corrupción en Venezuela ha creado una superautopista de cocaína a EE. UU. CNN en español. Recuperado de https:// cnnespanol.cnn.com/2019/04/17/la-corrupcion-en-venezuela-ha-creado-una-superautopista-de-cocaina-a-ee-uu/ 
se tiene evidencia de que los cárteles mexicanos, sobre todo el de Sinaloa y el Golfo, tienen presencia en ese país (Astorga, 2007). Aunado a esto, la porosidad de la frontera sur de México (Chiapas, Campeche y Quintana Roo) y la corrupción de autoridades aduanales y migratorias ha hecho que el trasiego aéreo, marítimo y terrestre de narcóticos por esos estados sea una constante desde hace décadas. El corredor centroamericano se ha sumado al tráfico ilegal de narcóticos por el Pacífico y por el Caribe.

Evidencia de la alta porosidad de la frontera sur de México y de la relevancia que ha adquirido esta ruta lo ilustra la situación de pequeñas poblaciones como Xcalak (Quintana Roo). Desde hace tres décadas es un secreto a voces la gran actividad de aeronaves que bombardean en el caribe mexicano narcóticos para que estos sean recogidos en lanchas o para deshacerse de la mercancía cuando están huyendo de alguna persecusión ${ }^{70}$. El estado de Quintana Roo, el cual tiene frontera terrestre con Guatemala y frontera terrestre y marítima con Belice es un espacio altamente cotizado por los cárteles mexicanos. Es tal la importancia geográfica que tiene Quintana Roo para las rutas del narcotráfico procedente de Sudamérica y Centroamérica que el poder corruptor del narcotráfico permeó a la clase política local del más alto nivel, un ejemplo de esto es el encarcelamiento en los EE. UU. del ex gobernador Mario Villanueva Madrid, quien fue acusado de coludir con el Cártel de Juárez, liderado por "el señor de los cielos". Pese a que estuvo en una prisión estadounidense Villanueva ha señalado que fue una venganza política en su contra $^{71}$.

De hecho, desde principios de 2020, la vulnerabilidad del espacio aéreo mexicano de la frontera sur quedó ampliamente evidenciada con el aterrizaje de una aeronave en una de las principales vías de comunicación terrestre de la zona la carretera Bacalar-Mérida y otra en Mahahual, ambas cargadas con cocaína. En el caso de la primer aeronave, ésta aterrizó en plena carretera automovilística y cuando acudieron militares a inspeccionar la nave fueron recibidos con disparos, incluso un militar resultó herido y otro falleció.

70 "La mercancía que sale de Xcalak se entrega en Chetumal y de ahí viaja hacia el norte o a Cancún, la tercera ciudad donde más cocaína se consume del país, según la encuesta nacional de adicciones. En la otra dirección, por una buena carretera, desde la capital de Quintana Roo se tarda unas 12 horas a Veracruz y otras tantas a Bronswille. En solo 24 horas ese kilo deja de valer 10.000 dólares en Xcalak y pasa a costar 60.000 en Texas" (García, 2019).

71 Ahrens, J. M. (23 de diciembre de 2016). Vuelve a México el gobernador del PRI al que compró el Señor de los Cielos. El País. Recuperado de https:/elpais.com/internacional/2016/12/23/ mexico/1482454032_605894.html?rel=mas 
A los pocos días una aeronave procedente de Argentina con destino a la isla de Cozumel fue identificada y obligada a aterrizar en el aeródromo de Mahahual (Quintana Roo) por aviones de la FAM.

Otra evidencia de esta vulnerabilidad es que en el último lustro diversas aeronaves han sido encontradas en territorio de Quintana Roo (México) o del vecino país de Belice. Algunas han sido halladas abandonadas, quemadas, otras se han estrellado, en tanto hay casos de aeronaves que incluso han aterrizado en el aeropuerto de Chetumal (capital administrativa de esa ese estado) y han sido abandonadas con cargamentos de cocaína. En los mapas de la figura 5.5, se muestra la presencia de aeronaves ilegales en la frontera entre México y Belice, estas son algunas aeronaves que han sido encontradas abandonadas, quemadas o que han tenido que realizar aterrizajes forzosos entre el 2013-20.

\section{Figura 5.5}

Aeronaves encontradas y usadas para el trasiego de drogas en la frontera México-Belice-Guatemala

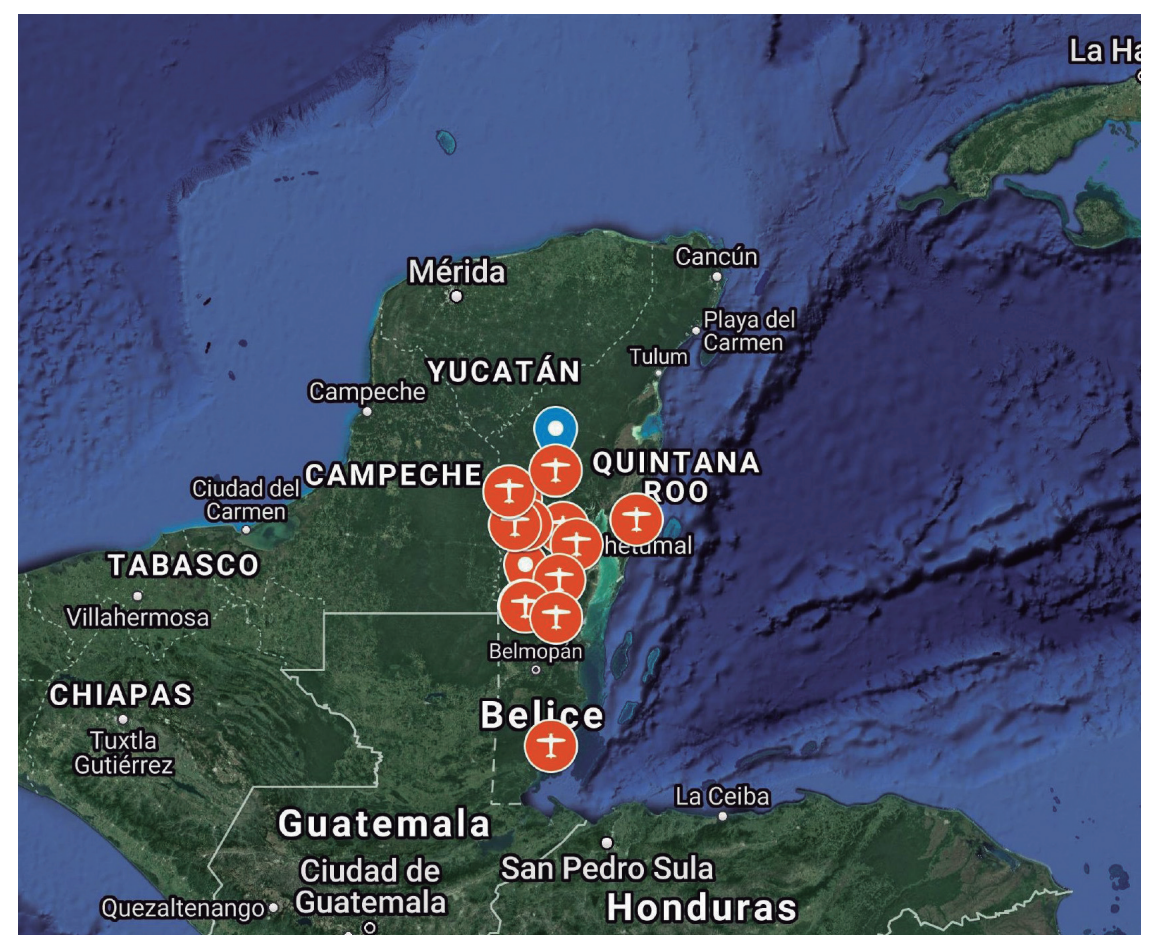






Nota: Elaboración propia a partir de diversas fuentes periodísticas.

En octubre de 2019 mediante una solicitud de información (folio 0000700266419) realizada a través de la Plataforma Nacional de Transparencia se solicitó la siguiente información: 1) número de aeronaves ilícitas detectadas por la SEDENA entre 2000 y 2019 desglosadas por cada año; 2) número de aeronaves ilícitas interceptadas por la SEDENA entre 2000 y 2019 desglosadas por cada año; 3) número de aeronaves no identificadas detectadas por la SEDENA entre 2000 y 2019 desglosadas por cada año; 4) número de aeronaves ilícitas rebeldes detectadas por la SEDENA entre 2000 y 2019 desglosadas por cada año; 5) número de aeronaves sospechosas identificadas por la SEDENA entre 2000 y 2019 desglosadas por cada año; 6) número de aeronaves ilícitas derribadas por la SEDENA entre 2000 y 2019 desglosadas por cada año; 7) número de aeronaves ilícitas identificadas por la SEDENA en el estado de Quintana Roo, entre 2000 y 2019, desglosadas por cada ańo, y 8) número de aeronaves ilícitas derribadas por la SEDENA en el estado de Quintana Roo, entre 2000 y 2019, desglosadas por cada año. 
La SEDENA respondió a los requerimientos 1, 2, 3, 5 y 7, respecto a los puntos 4, 6 y 8 se señaló que no se localizó registro o documento que dé respuesta a esos requerimientos. La información localizada se encuentra sintetizada en la tabla 5.5. Es pertinente destacar que las definiciones empleadas para solicitar dicha información son parte de la terminología oficial usada por la Fuerza Aérea Mexicana ${ }^{72}$.

Aeronave ilícita se refiere a toda aquella aeronave nacional o extranjera que habiendo sido considerada como sospechosa se interne a territorio nacional y que muestre además alguno de los siguientes indicios o condiciones: no contar con plan de vuelo, no reportarse a las autoridades aeronáuticas correspondientes, volar en espacios aéreos controlados sin autorización, no ajustarse a las altitudes mínimas establecidas, aeronaves con matrícula falsificada, cuando arroje cualquier objeto, cuando se declara rebelde a la aeronave y/o no tener activo código transponder.

La respuesta a la solicitud en torno a las aeronaves ilícitas detectadas y las aeronaves ilícitas interceptadas se presenta en la tabla 5.6.

\section{Tabla 5.5}

Número de aeronaves ilícitas detectadas y aeronaves ilícitas interceptadas entre 2001 y octubre de 2019

\begin{tabular}{|c|c|c|}
\hline Año & Aeronaves ilícitas detectadas & Aeronaves ilícitas interceptadas \\
\hline 2001 & 7 & 5 \\
\hline 2002 & 16 & 4 \\
\hline 2003 & 236 & 11 \\
\hline 2004 & 58 & 15 \\
\hline 2005 & 13 & 3 \\
\hline 2006 & 6 & 1 \\
\hline 2007 & 10 & 2 \\
\hline 2008 & 5 & 0 \\
\hline 2009 & 0 & 0 \\
\hline 2010 & 0 & 0 \\
\hline 2011 & 0 & 0 \\
\hline 2012 & 2 & 1 \\
\hline 2013 & 2 & 2 \\
\hline
\end{tabular}

72 Lo anterior con base en el Anexo del Memorándum de Entendimiento entre la SEDENA de México y el MINDEFENSA de Colombia para el intercambio de información y capacitación en materia de interdicción/interceptación aérea (2015). 


\begin{tabular}{|c|c|c|}
\hline Año & Aeronaves ilícitas detectadas & Aeronaves ilícitas interceptadas \\
\hline 2014 & 5 & 3 \\
\hline 2015 & 8 & 2 \\
\hline 2016 & 11 & 6 \\
\hline 2017 & 10 & 4 \\
\hline 2018 & 4 & 2 \\
\hline 2019 & 22 & 17 \\
\hline
\end{tabular}

Nota: Respuesta por parte de la SEDENA a la solicitud de información (folio 0000700266419) realizada a través de la Plataforma Nacional de Transparencia.

Aeronave no identificada se refiere a "toda aquella aeronave nacional o extranjera que origina su vuelo en territorio nacional y que sobrevuela el espacio aéreo mexicano, sin conocimiento de las autoridades aeronáuticas responsables". La respuesta a la solicitud en torno a las aeronaves no identificadas se presenta en la tabla 5.7. Lo cual indica que entre el 2001 y el 2019 se han detectado un total de 4,898 aeronaves no identificadas sobrevolando espacio aéreo mexicano.

\section{Tabla 5.6}

Número de aeronaves no identificadas detectadas entre 2001 y octubre de 2019

\begin{tabular}{|c|c|}
\hline Año & Aeronaves no identificadas \\
\hline 2001 & 570 \\
\hline 2002 & 525 \\
\hline 2003 & 280 \\
\hline 2004 & 215 \\
\hline 2005 & 208 \\
\hline 2006 & 232 \\
\hline 2007 & 187 \\
\hline 2008 & 220 \\
\hline 2009 & 268 \\
\hline 2010 & 282 \\
\hline 2011 & 166 \\
\hline 2012 & 293 \\
\hline 2013 & 542 \\
\hline
\end{tabular}




\begin{tabular}{|c|c|}
\hline Ańo & Aeronaves no identificadas \\
\hline 2014 & 390 \\
\hline 2015 & 216 \\
\hline 2016 & 85 \\
\hline 2017 & 53 \\
\hline 2018 & 108 \\
\hline 2019 & 58 \\
\hline
\end{tabular}

Nota: Respuesta por parte de la SEDENA a la solicitud de información (folio 0000700266419) realizada a través de la Plataforma Nacional de Transparencia.

Aeronave sospechosas se refiere a "toda aeronave nacional o extranjera procedente del exterior del país y que se dirija hacia territorio mexicano sin datos de plan de vuelo. Una aeronave adquiere el carácter de sospechosa, cuando no se apega a la reglamentación internacional, infringiendo uno de los siguientes puntos: no activar su código transponder, encender sus luces de navegación, no contar con plan de vuelo, no reportarse con las autoridades aeronáuticas correspondientes, volar en espacios aéreos controlados sin autorización y/o no ajustarse a las altitudes mínimas establecidas. La respuesta a la solicitud en torno a las aeronaves sospechosas identificadas se presenta en la tabla 5.8. Lo cual indica que entre el 2001 y el 2019 se han detectado un total de 1,598 aeronaves no identificadas sobrevolando espacio aéreo mexicano.

\section{Tabla 5.7}

Número de aeronaves sospechosas identificadas entre 2001 y octubre de 2019

\begin{tabular}{|c|c|}
\hline Año & Aeronaves sospechosas identificadas \\
\hline 2001 & 15 \\
\hline 2002 & 68 \\
\hline 2003 & 434 \\
\hline 2004 & 104 \\
\hline 2005 & 49 \\
\hline 2006 & 30 \\
\hline 2007 & 36 \\
\hline 2008 & 56 \\
\hline 2009 & 87 \\
\hline 2010 & 89 \\
\hline
\end{tabular}




\begin{tabular}{|c|c|}
\hline Año & Aeronaves sospechosas identificadas \\
\hline 2011 & 113 \\
\hline 2012 & 82 \\
\hline 2013 & 53 \\
\hline 2014 & 27 \\
\hline 2015 & 42 \\
\hline 2016 & 38 \\
\hline 2017 & 86 \\
\hline 2018 & 95 \\
\hline 2019 & 94 \\
\hline
\end{tabular}

Nota: Respuesta por parte de la SEDENA a la solicitud de información (folio 0000700266419) realizada a través de la Plataforma Nacional de Transparencia.

En el caso de la frontera sur de México, específicamente del estado de Quintana Roo, se solicitó el número de Aeronaves ilícitas identificadas. La respuesta a esa solicitud de información se expresa en la tabla 5.9. Según la información proporcionada, entre 2001 y octubre de 2019 solamente se han identificado siete aeronaves ilícitas en Quintana Roo. Dicha información contrasta con el número de aeronaves que se han encontrado abandonadas, se han estrellado, han sido quemadas u obligadas a aterrizar por distintas cuestiones. Siete aeronaves ilícitas identificadas en 19 ańos, resulta una cifra cuestionable si se triangula con la enorme actividad aérea ilegal que según otras de las fuentes empleadas en esta investigación se presenta a través de la frontera sur de México y concretamente en el estado de Quintana Roo.

\section{Tabla 5.8}

Aeronaves ilícitas identificadas en el estado de Quintana Roo

\begin{tabular}{|c|c|}
\hline Año & Aeronaves ilícitas identificadas en el estado de Quintana Roo \\
\hline 2001 & 0 \\
\hline 2002 & 0 \\
\hline 2003 & 0 \\
\hline 2004 & 0 \\
\hline 2005 & 0 \\
\hline 2006 & 0 \\
\hline
\end{tabular}




\begin{tabular}{|c|c|}
\hline Año & Aeronaves ilícitas identificadas en el estado de Quintana Roo \\
\hline 2007 & 1 \\
\hline 2008 & 1 \\
\hline 2009 & 0 \\
\hline 2010 & 0 \\
\hline 2011 & 0 \\
\hline 2012 & 0 \\
\hline 2013 & 1 \\
\hline 2014 & 1 \\
\hline 2015 & 0 \\
\hline 2016 & 0 \\
\hline 2017 & 0 \\
\hline 2018 & 2 \\
\hline 2019 & 1 \\
\hline
\end{tabular}

Nota: Respuesta por parte de la SEDENA a la solicitud de información (folio 0000700266419) realizada a través de la Plataforma Nacional de Transparencia.

Peor aún, la falta de correspondencia entre la actividad ilegal documentada con fuentes periodísticas y la información oficial, serían una muestra de que esas aeronaves no fueron detectadas al momento de ingresar a espacio aéreo mexicano y, en consecuencia, no fueron catalogadas como aeronaves ilícitas identificadas.

Frente a la actividad de aeronaves ilegales que se hizo pública en diversos noticieros mexicanos a principios del 2020, la SEDENA ha insistido en publicitar, en diversos medios de comunicación, que la FAM dispone de un sistema de vigilancia que ha permitido identificar las trazas sospechosas. Sin embargo, esta información contrasta, incluso se contrapone, con el reconocimiento que la propia FAM ha hecho de la vulnerabilidad y la falta de capacidades para controlar más de dos terceras partes del espacio aéreo mexicano, lo que ha hecho de la frontera sur de México se haya convertido en una zona ideal para el tráfico aéreo ilegal de drogas provenientes de Sudamérica.

Las condiciones geográficas de la zona hacen que acceder a este espacio, desde Colombia o Venezuela, sea bastante factible tanto por vía aérea como por vía marítima, ya sea en lanchas rápidas o en sumergibles. Para acceder por vía aérea se están usado aeronaves de turbina tipo Gulfstream y Learjet a fin 
de reducir el tiempo de viaje. El negocio es tan rentable que muchas de estas aeronaves terminan abandonadas o quemadas una vez el producto ilícito que transportan ha sido desembarcado.

También se ha publicitado, a través de diversas notas periodísticas e incluso de videos grabados por la SEDENA, el SIVA calificándolo como "el sofisticado sistema del ejército mexicano para cazar narcoavionetas", el cual dispone de 80 elementos que operan el sistema de control, cómputo, comunicaciones, inteligencia y reconocimiento con el objetivo de detectar a las aeronaves que sobrevuelan el país y sean sospechosas de actividades ilegales ${ }^{73}$. En un conocido noticiero mexicano (En Punto-Televisa) se hizo público el video de la aeronave que aterrizó en la carretera Bacalar-Mérida y que según se señala en dicho material videográfico había sido identificada previo a su ingreso a espacio aéreo mexicano ${ }^{74}$.

Por otra parte, según una nota periodística publicada recientemente en La Jornada (2 de febrero de 2020) se señala que "La FAM consolidará este año la vigilancia del espacio aéreo nacional"75. Según esta nota esa consolidación se va a lograr a través del mantenimiento a las plataformas aéreas Embraer ${ }^{76}$ y mediante la probable instalación de dos nuevos sistemas de radar en el sureste del país (su concreción depende del apoyo que se brinde por autoridades de EE. UU.). La actualización de los sensores de los tres sensores de las plataformas aéreas Embraer permitiría mejorar la precisión en determinar la altura del blanco y en la localización de blancos aéreos y marítimos. Se pasaría de una distancia de detección de 200 a 450 kilómetros y la capacidad de monitoreo pasaría de 300 a 500 trazas (C.G FAM, 2018, p. 120). Para lograr

73 Infobae. (1 de febrero de 2020). SIVA: así funciona el sofisticado sistema del ejército mexicano para cazar narco avionetas. Infobae. Recuperado de https://www.infobae.com/america/ mexico/2020/02/01/siva-asi-funciona-el-sofisticado-sistema-del-ejercito-mexicano-para-cazar-narco-avionetas/

74 Noticieros Televisa. (10 de febrero de 2020). SEDENA interceptó avioneta con droga en la carretera Bacalar - Mérida [Archivo de video]. Recuperado de https://www.youtube.com/watch?v=yM7Y8R49ji0

75 Castillo, G. y Murillo, E. (2 de febrero de 2020). La FAM consolidará este año la vigilancia del espacio aéreo nacional. La Jornada. Recuperado de https://www.jornada.com. $\mathrm{mx} / 2020 / 02 / 02 /$ politica/007n1pol

76 La FAM licitó el mantenimiento especializado de las tres plataformas EMB-145 para dotarlas paulatinamente de sistemas avanzados ERIEYE y FLIR para potenciar sus capacidades. En junio de 2018 las plataformas fueron sometidas a mantenimiento mayor. El servicio incluyó la reparación y corrección de errores y desgaste en los sensores de los aparatos. El mantenimiento a los sensores en las plataformas EMB-145 es el más costoso al que se ha sometido a las aeronaves de la FAM, ya que significa una inversión de 4,752,7 millones de pesos (unos 224 millones de euros) que comenzó hace tres años y deberá concluir en 2020 (Medellín, 2019). 
una mayor efectividad en la detección de vuelos sospechosos y/o ilegales el SIVA mantiene comunicación constante con sus contrapartes de EE. UU., Colombia, Brasil, Perú, Panamá y Guatemala.

Como se ha evidenciado, la vía aérea ha sido una de las más utilizadas por el crimen transnacional para el tráfico de narcóticos y/o de precursores químicos $^{77}$. Sin embargo, está no se circunscribe a aeronaves y vuelos ilegales. Hay información que evidencia que algunas aerolíneas, pilotos, sobrecargos, agentes aduanales, personal aeroportuario y agentes policiacos han estado involucrados en actividades ilegales relacionadas con el narcotráfico. En el caso mexicano, incluso se ha identificado que los principales aeropuertos del país sirven para estas operaciones y son un espacio controlado por las mafias del narcotráfico (Ravelo, 2016). Aeropuertos como el de Ciudad de México, Cancún (Quintana Roo) y Tijuana (Baja California) están entre los que mayor presencia de narcóticos ha sido identificada ${ }^{78}$.

\section{La Cooperación Bilateral México y Colombia}

Además de los fuertes lazos históricos, sociales y culturales que comparten Colombia y México, ambos países comparten amenazas y desafíos en común, entre ellos los representados por grupos transnacionales del crimen organizado, en especial los que se dedican a la producción y tráfico ilícito de narcóticos y armas. Para el caso de esta investigación concretamente se hace énfasis en la amenaza que representa el trasiego de droga por vía aérea y la forma en que la Fuerza Aérea de Colombia (FAC) y la FAM hacen frente a este desafío transnacional, tanto a nivel nacional, como en materia de la cooperación binacional que se ha venido desarrollando en los últimos años entre ambos países.

Lo anterior se ve ilustrado por la formalización y el aumento de la cooperación militar y policial entre Colombia y México. Es de destacar el papel que Colombia ha adquirido en los últimos años como un país que, a través

77 Los precursores químicos son sustancias y productos químicos esenciales que pueden ser utilizados por la industria, las farmaceuticas y con fines cientificos; no obstante, también dadas sus características y componentes, con frecuencia se utilizan en la elaboración de estupefacientes (Subsecretaría de lucha contra el Narcotráfico, 2016).

78 García, J. (22 de junio de 2019). El Caribe turbio. El País. Recuperado de https://elpais.com/ internacional/2019/06/18/actualidad/1560851881_870643.html 
de la cooperación bilateral y multilateral, es exportador de aprendizajes y de buenas prácticas en materia de seguridad y combate al crimen organizado. En opinión de Arlene Tickner, los mecanismos de cooperación Sur-Sur y triangulada que ha desarrollado Colombia, de la mano de los EE. UU., se expresan en la exportación de la experticia policial y militar, lo cual también se ha convertido en una pieza central por ganar reconocimiento regional e internacional como un hacedor de seguridad (Tickner, 2016).

En las últimas dos décadas la cooperación en el área de seguridad entre Colombia y México se ha venido afianzando gradualmente. Sin embargo, esta cooperación se incrementó y visibilizó notoriamente durante el mandato presidencial de Felipe Calderón Hinojosa (2006-12), cuyo mandato coincidió temporalmente con el del presidente colombiano Álvaro Uribe Vélez (2006-10) y su política de Seguridad Democrática. Esta cooperación se reflejó en la capacitación de policías federales y de militares mexicanos por sus contrapartes de Colombia. La participación de Colombia como exportador de seguridad no sólo ha incentivado la cooperación bilateral, sino la cooperación triangular (Estados Unidos, Colombia y México) y de una emergente cooperación cuatripartita (Estados Unidos, Colombia, México y Guatemala) [Tickner, 2016].

Aunque los círculos de seguridad mexicana se han caracterizado por su recelo a la intervención de otros países en asuntos de seguridad interna, en las últimas tres décadas el vínculo con Washington se ha hecho mucho más estrecho y visible en materia de seguridad, enmarcado en la "lucha contra las drogas". Desde 1995 se dio un notorio acercamiento entre los ejércitos de EE. UU. y de México para cooperar en programas de entrenamiento de militares para contrainsurgencia y narcotráfico y un programa piloto de combate a las drogas en Chihuahua. Sin embargo, en 1997 es detenido el general Jesús Gutiérrez Rebollo, encargado del Instituto Nacional de Combate a las Drogas (INCD), por sus vínculos con Amada Carrillo Fuentes (Astorga, 2016), lo cual evidenció el alto grado de penetración que las organizaciones criminales tenían sobre las instituciones encargadas de hacerles frente $^{79}$. Pese a estos episodios de desconfianza, EE. UU. ha mantenido la cooperación con México y este país, a su vez, ha reducido su margen de

79 En opinión de Luis Astorga "Los militares no tienen el poder mágico de controlar la demanda en Estados Unidos, en México, ni en cualquier otro lugar. Las fuerzas armadas corren evidentemente el riesgo de ver incrementados los niveles de corrupción en sus filas, y en el peor de los casos de ser el espacio de articulación de fuertes intereses relacionados con el tráfico de drogas, que desplazaría su centro de gravedad del campo de la vieja estructura política hacia las fuerzas 
autonomía frente a las demandas estadounidenses de aumentar los esfuerzos en la lucha contra las drogas, a tal grado que durante la presidencia de Vicente Fox se mantuvo la militarización de la seguridad pública, la SEDENA incrementó su participación en actividades de combate al narcotráfico y se inició la implementación gradual de una estrategia de captura de blancos prioritarios.

En el caso de Colombia, la cooperación entre agencias de seguridad mexicanas y colombianas se ha venido haciendo más estrecha, ya que las organizaciones de seguridad colombianas son vistas como un interlocutor con experiencia y vistos con menos recelo que la contraparte estadounidense, ya que no se considera que la cooperación colombiana tenga fines intervencionistas en la política interna de México.

Además, indiscutiblemente, en materia de vigilancia e interdicción aérea la FAC ha desarrollado unas capacidades y experiencias que la ubican como un referente regional en operaciones aéreas en contra del narcotráfico. En el caso colombiano desde la década de 1990 se encuentran los primeros antecedentes en materia de vigilancia aérea (ver capítulo tres). Para reducir el tráfico aéreo ilegal de cocaína EE. UU. comenzó a operar, en 1990, el Air Bridge Denial Program (ABDP) en Colombia y Perú. Este programa tenía como objetivo identificar aeronaves sospechosas de tráfico de drogas y obligarlas a aterrizar, incluso usando fuerza letal de ser necesario (GAO, 2005).

Con el citado apoyo estadounidense se iniciaron vuelos de aeronaves AWACS de la USAF, P-3 y C-550 de US CUSTOMS, con operadores de la defensa aérea de Colombia, Ecuador y Perú, cuyo objetivo era hacer frente a las actividades aéreas ilegales de trasiego de narcóticos. Como parte del estrecho vínculo de cooperación militar entre EE. UU. y Colombia se instalaron radares TPS 43 y TPS 70 en Puerto Salgar, en 1989, en Villavicencio y Barranquilla, en 1990, cuya operación de vigilancia y seguimiento estaba a cargo de la FAC (Quintero, 2018).

En 1991 se implementa la operación andina "Plan Águila”, cuyo propósito primordial era el control de vuelos ilegales desde Ecuador, Perú y Colombia. Para ello se instalaron, con apoyo estadounidense, radares en Colombia en Tres Esquinas, Larandia y Araracuara (Caquetá), también en Leticia (Amazonas); en Iquitos (Perú) y Lago Agrio (Ecuador), con el objetivo de hacer interdicción a los vuelos ilegales (Quintero, 2018). Sin embargo, este

armadas y otros aparatos de seguridad integrados especialmente por militares” (2016, p. 223). 
programa junto con el ABDP, se suspendieron en abril de 2001 después de que un avión civil legítimo fue derribado en Perú, matando a dos ciudadanos estadounidenses (ver capítulos uno y dos). En agosto de 2003, Colombia y EE. UU. iniciaron las operaciones del Air Bridge Denial (ABD) en Colombia luego de firmar un Acuerdo delineando las responsabilidades y medidas de seguridad (GAO, 2005). Las operaciones del ABD redujeron las trazas de interés desconocida (TID) observadas fuera del espacio aéreo colombiano y las Trazas Sospechosas (TS) en el espacio aéreo colombiano, como se evidencia en las gráficas 5.6 y 5.7 .

\section{Gráfica $\mathbf{5 . 6}$}

Trazas de interés desconocidas identificadas por la Fuerza Aérea Colombiana entre 2008 y 2014.

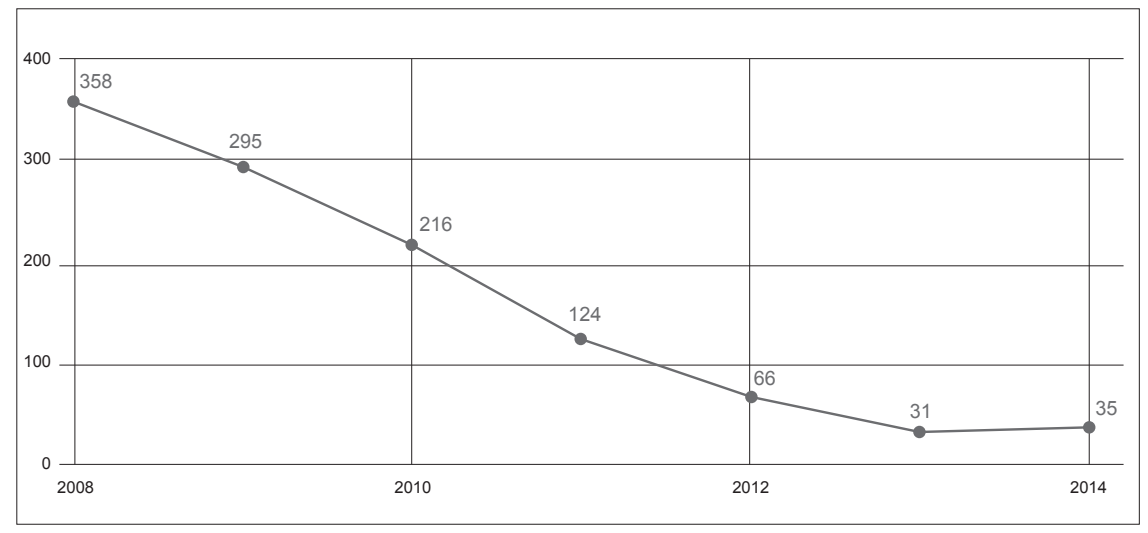

Nota: Organización de Estados Americanos (2014). Lecciones Aprendidas en la lucha contra el Narcotráfico Fuerza Aérea Colombiana. Comisión Interamericana para el Control del Abuso de las Drogas. Quincuagésimo Sexto Período Ordinario de Sesiones. 19 al 21 de noviembre de 2014. Guatemala. 


\section{Gráfica 5.7}

Vuelos ilegales sobre territorio colombiano detectados por la Fuerza Aérea colombiana entre 2003 y 2014.

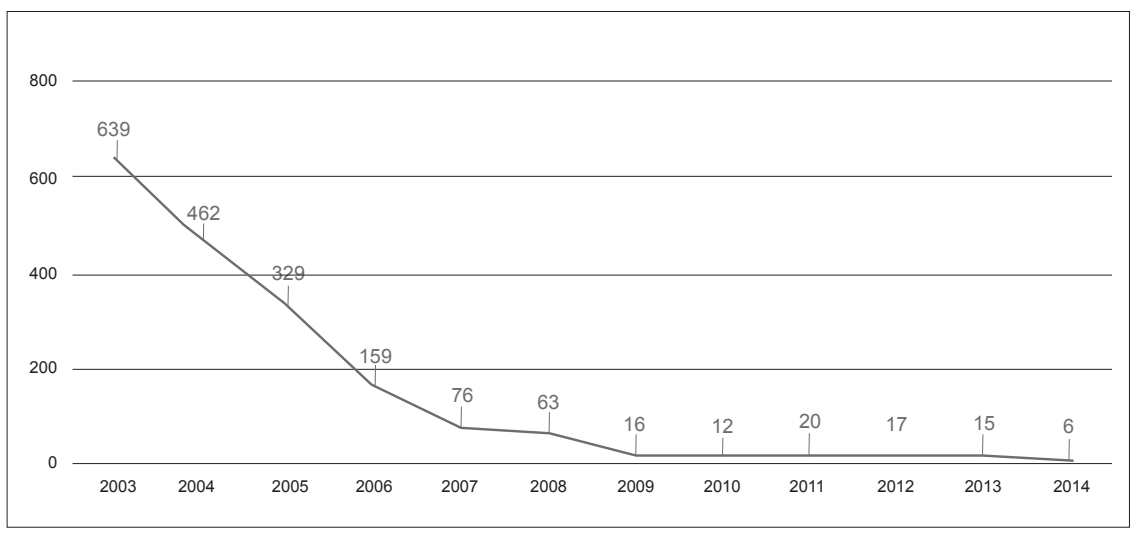

Nota: Organización de Estados Americanos (2014). Lecciones Aprendidas en la lucha contra el Narcotráfico Fuerza Aérea Colombiana. Comisión Interamericana para el Control del Abuso de las Drogas. Quincuagésimo Sexto Período Ordinario de Sesiones. 19 al 21 de noviembre de 2014. Guatemala.

En materia de cooperación internacional la FAC realiza actividades de entrenamiento, operaciones combinadas, entrega de objetivos a otros países e intercambio de cooperación. Cabe destacar que también ha establecido vínculos con diversos países de la región andina, de Centroamérica y recientemente con México (ver capítulo dos). Como parte de este incremento en la cooperación en materia de seguridad entre Colombia y México, se puede destacar que recientemente estos países suscribieron el Memorándum de Entendimiento sobre Cooperación Mutua en Materias de Seguridad y Defensa entre las Secretaría de la Defensa Nacional y la Secretaría de Marina de los Estados Unidos Mexicanos y el Ministerio de Defensa Nacional de la República de Colombia ${ }^{80}$ para fortalecer la cooperación en seguridad y defensa, el cual se firmó en julio de 2015. Según lo establecido en este documento se tiene como objetivo "establecer las bases mediante las cuales los Participantes harán sus mejores esfuerzos para llevar a cabo el intercambio de información, experiencias y capacitación en materias de seguridad y defensa”.

80 Documento obtenido a través de una solicitud de acceso a la información con número de folio 000050072319 presentada a través de la Plataforma Nacional de Transparencia México. 
Además, como parte del fortalecimiento de la cooperación entre ambos países, el 27 de septiembre de 2015, se firmó el Memorándum de Entendimiento entre la Secretaría de la Defensa Nacional de los Estados Unidos Mexicanos y el Ministerio de Defensa Nacional de la República de Colombia para el Intercambio de Información y Capacitación en Materia de Interdicción/Interceptación Aérea ${ }^{81}$. En el documento se establece que "tiene como objetivo establecer los procedimientos con base en los cuales las Partes llevarán a cabo el intercambio de información y la capacitación del personal en materia de interdicción/ interceptación aérea, sobre la base de equidad y beneficio mutuo". Según los establecido en el Artículo III del citado Memorándum las modalidades de cooperación son las siguientes:

- Intercambio de información y experiencias en diversos ámbitos relacionados con la interdicción/ interceptación de aeronaves;

- Intercambio de documentación y de material de interés común para las Partes;

- Participación de personal militar en cursos de capacitación, seminarios, conferencias y simposios;

- Participación de observadores militares en ejercicios de interdicción/ interceptación de aeronaves y

- Cualquier otra modalidad que las partes acuerden.

En el artículo V se establece el procedimiento para llevar a cabo el proceso de interdicción/interceptación. Dicho procedimiento consiste en lo siguiente: Inicio cita

En caso de que una de las Partes detecte una aeronave proveniente de los Estados Unidos Mexicanos o de la República de Colombia, sospechosa de ser empleada en actividades ilícitas, que sobrevuele el espacio aéreo de alguno de esos Estados o cuyo rumbo de vuelo proyecte ingresar a su espacio aéreo, lo informará de inmediato a la otra parte, a través de sus autoridades responsables.

Cuando para el seguimiento de una aeronave sospechosa las autoridades responsables de cada parte hayan intercambiado información, estas elaborarán un informe con el fin de evaluar los aspectos positivos, negativos, resultados

81 Respuesta a solicitud de acceso a la información con número de folio 000050072319 presentada a través de la Plataforma Nacional de Transparencia México. 
obtenidos recomendaciones para futuras coordinaciones en el intercambio de información.

Las Partes deberán observar en todo momento lo dispuesto en las Convenciones Internacionales aplicables de las que los Estados Unidos Mexicanos y la República de Colombia son parte, particularmente lo dispuesto en el Convenio sobre Aviación Civil Internacional, abierto a firma en Chicago, el 7 de diciembre de 1944 .

Fin cita

Las Partes, siempre que lo estimen pertinente y de conformidad con lo dispuesto en la legislación nacional, podrán compartir información proporcionada por terceros Estados, relacionada con el objetivo del presente Memorándum.

La materialización de esta cooperación se ha reflejado en intercambios de experiencias en capacidades aéreas. Por sólo citar un ejemplo, en diciembre de 2010, la FAM envió a un grupo de 24 pilotos para recibir entrenamiento de la FAC en la escuela de helicópteros ubicada en Melgar (Guevara, 2011). Otro ejemplo de cooperación son los ejercicios binacionales entre la FAC y la FAM como el denominado "MEXCOL I", realizado del 21 al 25 de noviembre de $2016^{82}$. Este es un ejercicio con la final de realizar actividades de control del espacio aéreo sobre TS mediante ejercicios de simulación virtual para entrenar y aplicar los procedimientos que permitan una mayor eficacia para combatir los tráficos ilícitos transnacionales ${ }^{83}$. Posteriormente, del 22 al 26 de mayo de 2017, en Tuxtla Gutiérrez (México) se realizó otro ejercicio conjunto "MEXCOL II" ${ }^{44}$ sobre TS simulados en los espacios aéreos de México y Colombia, por medio de ejercicios simulados para mejorar la coordinación operacional entre los centros de operaciones de ambos países, haciendo uso de los medios de detección, identificación, seguimiento e interceptación del tráfico ilícito transnacional ${ }^{85}$.

82 Ministerio de Defensa Nacional. (22 de noviembre de 2016). Fuerza Aérea Colombiana. Inicio del ejercicio binacional simulado de interdicción aérea. Recuperado de https://www. fac.mil.co/inicio-del-ejercicio-binacional-simulado-de-interdicci $\% \mathrm{C} 3 \% \mathrm{~B} 3 \mathrm{n}-\mathrm{a} \% \mathrm{C} 3 \% \mathrm{~A}$ 9rea-mexcol-i

83 Ministerio de Defensa Nacional. Fuerza Aérea Colombiana (2018). Logros FAC 2006-2018 y Retos FAC 2018. Recuperado de https://www.justiciamilitar.gov.co/irj/go/km/docs/Mindefensa/Documentos/descargas/Sobre_el_Ministerio/RendicionCuentas/2018/FAC/LogrosFAC2018.pdf

84 Webinfomil. (28 de mayo de 2017). Fuerzas Aéreas de Colombia y México realizaron ejercicio simulado de interdicción Mexcol II. Recuperado de http://www.webinfomil.com/2017/05/ fuerzas-aereas-de-colombia-y-mexico.html 
Durante la administración del presidente Andrés Manuel López Obrador (2018-24), se ha continuado con la cooperación bilateral con Colombia. Por ejemplo, del 6 de mayo al 7 de junio de 2019, seis Oficiales mexicanos realizaron un curso de Inteligencia Aérea en Colombia. Además, desde el 6 de julio de 2019 hasta el 27 de marzo de 2020, cuatro Oficiales realizan el curso de Entrenamiento Inicial de Ala Rotativa (IERW-CN-1004)” en Melgar, Colombia ${ }^{86}$.

Según información que la SEDENA ha hecho pública en los últimos seis ańos se detectaron en espacio aéreo mexicano 1356 vuelos relacionados con actividades de narcotráfico. En 92 de los casos se detectó cocaína, metanfetamina, marihuana y heroína. Durante la administración del presidente AMLO, se han detectado 630 vuelos sospechosos, de los cuales 80 eran ilí$\operatorname{citos}^{87}$. Estas cifras indican que las actividades de aeronaves ilegales se mantienen como un desafío para la seguridad nacional mexicana y un problema transnacional compartido con Colombia y con otros países de Sudamérica y Centroamérica. Por lo tanto, es de esperar que en los próximos años la cooperación bilateral entre México y Colombia en materia de vigilancia e interdicción aérea continué y se haga más estrecha. La experiencia de Colombia en esta materia seguirá siendo muy importante para el fortalecimiento de las capacidades de interdicción aérea de otros países de la región, entre ellos México.

\section{Conclusiones}

Con el final de la Guerra Fría y la redefinición de la agenda de seguridad de EE. UU. el combate al tráfico de narcóticos se colocó en el top de la agenda. Esto tuvo repercusiones inmediatas en diversos países de la región, en especial en los países de la zona andina, en Centroamérica y en México,

y Retos FAC 2018. Recuperado de https://www.justiciamilitar.gov.co/irj/go/km/docs/Mindefensa/Documentos/descargas/Sobre_el_Ministerio/RendicionCuentas/2018/FAC/LogrosFAC2018.pdf

86 Secretaría de la Defensa Nacional [SEDENA]. (2020a). Primer Informe de Labores 20182019. México. Recuperado de http://www.sedena.gob.mx/pdf/informes/primer_informe_labores.pdf

87 Infobae (1 de febrero de 2020). SIVA: así funciona el sofisticado sistema del ejército mexicano para cazar narco avionetas. Infobae. Recuperado de https://www.infobae.com/america/ mexico/2020/02/01/siva-asi-funciona-el-sofisticado-sistema-del-ejercito-mexicano-para-cazar-narco-avionetas/ 
ya que estos países eran origen y tránsito del tráfico de narcóticos, en especial de la cocaína que presentaba altos niveles de consumo y demanda entre la sociedad estadounidense.

En ese contexto de "guerra contra las drogas", desde los EE. UU. comienza a impulsarse el desarrollo de capacidades para que países como Colombia, Ecuador, Perú y México comenzarán a hacer frente a la producción y trasiego de narcóticos. Una de las áreas donde se puso mayor atención fue en el tráfico que se realizaba por vía aérea a través de diversas rutas (Caribe, Pacífico, Centroamérica, México).

Las primeras operaciones de interdicción aérea en países como Colombia, Perú, Ecuador y México tienen sus orígenes en la década de 1990. Si bien en un primer momento el gobierno estadounidense trató de implementar la interdicción aérea como un proyecto regional, la reticencia que enfrentaron en varios países estas operaciones por cuestiones de soberanía derivó en que estas se fueran implementando gradualmente y de manera bilateral o multilateral. Lo que se encuentra es que los países latinoamericanos que más acogida dieron inicialmente a la cooperación estadounidense en materia de interdicción aérea fueron Colombia y Perú. Aunque se profundizó y desarrolló más ampliamente en Colombia.

El proceso de aprendizaje y especialización que ha desarrollado Colombia en materia de interdicción aérea, lo llevaron a posicionarse como un referente para la región y como un país exportador de conocimientos y capacidades en esta materia. En contraste, México, pese a ser el principal país de tránsito terrestre y aéreo de narcóticos hacia los EE. UU., no tiene un control pleno de su espacio aéreo. De hecho, México solo tiene una cobertura del 32\% del espacio aéreo nacional, lo cual, se ha presentado como una ventana de oportunidad para que las organizaciones criminales se arriesguen a hacer uso ilegal del espacio aéreo mexicano, mediante aeronaves procedentes de Sudamérica y Centroamérica.

Esta vulnerabilidad ha sido reconocida por el gobierno mexicano y por la propia Secretaría de la Defensa Nacional y la Secretaría de Marina. Ante este escenario, conocido por las autoridades estadounidenses y mexicanas desde la década de 1990, surgieron los primeros intentos para la realización de operaciones de vigilancia y control aéreo. Sin embargo, estos no comenzaron a fructificar tan rápido como en Colombia, en parte debido a las reservas que la clase política y las fuerzas armadas mexicanas tienen hacia Estados Unidos. Fue casi una década después de este primer antecedente, que en 2004, se creó el Centro de Mando y Control del Sistema Integral de Vigilancia Aérea con la 
finalidad de mejorar las capacidades de vigilancia y control del espacio aéreo mexicano. Aunque el proceso de implementación fue más lento que el que se presentó en otros países, esto permitió que el SIVA dispusiera de mayor autonomía, sin dejar de reconocer la relevancia que tiene la cooperación con otros países, respecto a la propuesta inicial hecha en los años noventa donde los EE. UU. podría tener una injerencia más marcada.

Con el aumento del poder de los cárteles mexicanos, las disputas entre éstos por el control del tráfico de drogas aumentaron, con la consecuente exacerbación de la violencia que se generó y que se visibilizó ampliamente desde el 2008 hasta la fecha. Con la llegada de Felipe Calderón a la presidencia de México (2006-12) el ejecutivo declaró una guerra contra el crimen organizado; en consecuencia, se dio un mayor involucramiento de las fuerzas armadas en labores de seguridad pública. Esto, a su vez, propició una ventana de oportunidad para modernizar los recursos, infraestructura y presupuesto de las fuerzas armadas, entre ellas la Fuerza Aérea Mexicana. En los últimos 16 años la FAM ha incrementado sus capacidades en materia de vigilancia, control e interdicción aérea, mediante la modernización de sus aeronaves de ala fija y rotatorias, la creación de un escuadrón de Sistemas Aéreos No Tripulados, el aumento en las horas de vuelo y la capacitación de su personal a través de convenios de colaboración con diversos países, entre los que destacan EE. UU., Colombia y Brasil. No obstante, este proceso de modernización no ha sido culminado y se tienen varios procesos pendientes para poder mejorar cuestiones como aumentar la cobertura del espacio aéreo mexicano, incrementar el número de plataformas aéreas y actualizar los radares de los que se dispone actualmente.

Hay evidencia de que el trasiego de drogas por vía aérea procedente de Venezuela, Colombia, Bolivia y Perú, se mantiene aprovechando la ventana de oportunidad que se presenta para hacer uso del espacio aéreo de países como Belice, Guatemala, El Salvador y Honduras, como puente para hacer llegar la droga hacia México y posteriormente hacia Estados Unidos. De hecho, la frontera sur de México presenta una alta porosidad para el tráfico de narcóticos por vía terrestre y marítima, pero tal parece que también por la vía aérea, ya que el análisis de diversas fuentes consultadas evidencia que desde los años noventa se ha presentado una gran actividad de vuelos ilegales procedentes de Centroamérica y Sudamérica que ingresan al espacio aéreo mexicano. Esto sumado al uso que los cárteles mexicanos hacen del espacio aéreo mexicano para el traslado de narcóticos desde el sur, el centro y el norte del país hacia Estados Unidos. 
El contexto descrito indicaría que continuar con el proceso de modernización del personal e infraestructura de FAM, así como con el aumento de las capacidades del SIVA, tendría que ser una prioridad para el Estado mexicano, independientemente del partido que esté en el poder. Sin embargo, con la llegada de AMLO a la presidencia de México aún no es del todo claro si se mantendrá este proceso de modernización de la FAM, ya que uno de los principales ejes de la retórica del nuevo gobierno es el de la austeridad. Una señal positiva es que el presidente López Obrador ha mantenido hasta ahora una buena relación con el Ejército mexicano, al cual ha reconocido públicamente por su lealtad a las instituciones y su respaldo a las acciones de su gobierno. Además, durante el primer año de su gestión se han mantenido las relaciones de cooperación entre la FAM y la FAC, lo cual indica que la relación de cooperación que se ha venido construyendo entres estos países se mantendrá y se seguirá afianzando, sobre todo porque los efectos negativos que genera el narcotráfico son de carácter transnacional y, por tanto, se requiere de esfuerzos conjuntos para hacer frente a la amenaza a la seguridad y paz interior que representan las organizaciones criminales de México y Colombia.

\section{Referencias}

Aguilar, H. y Meyer, L. (1991). A la sombra de la revolución mexicana. México: Editorial Cal y Arena.

Ahrens, J. M. (23 de diciembre de 2016). Vuelve a México el gobernador del PRI al que compró el Señor de los Cielos. El País. Recuperado de https:// elpais.com/internacional/2016/12/23/mexico/1482454032_605894.ht$\mathrm{ml}$ ?rel=mas

Astorga, L. (2005). El siglo de las drogas: El narcotráfico del Porfiriato al nuevo milenio. México: Plaza \& Janes.

Astorga, L. (2007). Seguridad, traficantes y militares: el poder y la sombra. México: Tusquets Editores.

Astorga, L. (2016). El siglo de las drogas. Del porfiriato al nuevo milenio. México: Penguin Random House Debolsillo.

Bailey, J. (2014). Crimen e impunidad. Las trampas de la seguridad en México. México: Debate

Castillo, G. y Murillo, E. (2 de febrero de 2020). La FAM consolidará este año la vigilancia del espacio aéreo nacional. La Jornada. Recuperado de https://www.jornada.com.mx/2020/02/02/politica/007n1pol 
Chabat, J. (2000, 31 de marzo). La guerra imposible. Letras Libres. Recuperado de http://www.letraslibres.com/revista/convivio/la-guerra-imposible

Centro de Investigaciones Económicas y Políticas de Acción Comunitaria [CIEPAC], Centro Nacional de Comunicación Social [CENCOS] (comps). [2002]. Siempre cerca, siempre lejos: Las Fuerzas Armadas en México. Ed. Global Exchange, CIEPAC, CENCOS. México.

Comando General de la Fuerza Aérea Mexicana [CG FAM]. (2018). En: R. Sodi (coordinador), La Fuerza Aérea en la Defensa del Estado. México: Editorial Porrúa.

García, D. (27 de diciembre de 2017). Así operan los cárteles colombianos y mexicanos en aeropuertos. El Universal. Recuperado de https://www. eluniversal.com.mx/nacion/seguridad/de-alto-vuelo-las-redes-del-narcoen-aeropuertos

García, J. (22 de junio de 2019). El Caribe turbio. El País. Recuperado de https://elpais.com/internacional/2019/06/18/actualidad/1560851881_870643.html

General Accountability Office [GAO]. (2005). Drug Control: Air Bridge Denial Program in Colombia Has Implemented New Safeguards, but Its Effect on Drug Trafficking Is Not Clear. United States of America. Recuperado de https://www.gao.gov/products/gao-05-970

General Accountability Office [GAO]. (1993). Drug Control. Revised Drug Interdiction Approach is Needed in México United States of America. Recuperado de https://www.gao.gov/products/NSIAD-93-152

Gobierno de México. (22 de abril de 2019). Catálogo de aeronaves susceptible de venta. Recuperado de https://www.gob.mx/banobras/documentos/catalogo-de-aeronaves-susceptibles-de-venta

González, L. (2018). El poder aéreo. En: R. Sodi (coordinador), La Fuerza Aérea en la Defensa del Estado (pp. 51-56). México: Editorial Porrúa.

Guerrero, E. (1 de junio de 2011). La raíz de la violencia. Revista Nexos. México. Disponible en http://www.nexos.com.mx/?p=14318

Guevara, I. (2011). Adapting, transforming and modernizing under fire: the mexican military 2006-2011. Strategic Studies Institute. U.S. Army War College, Carlisle, PA. The Lefort Papers. United States of America.

Guevara, I. (11 de julio de 2015). Los drones de México: quién los utiliza y por qué. Animal Político. Recuperado de https://www.animalpolitico. com/2015/07/los-drones-de-mexico-quien-los-utiliza-y-por-que/ 
Guevara, I. (2016). A Bond Worth Strengthening. Understanding the Mexican Military and U.S.-Mexican Military Cooperation. Wilson Center. Mexico Institute. United States of America.

Hernández, A. (2014). Los señores del narco. México: Grijalbo.

Infobae (1 de febrero de 2020). SIVA: así funciona el sofisticado sistema del ejército mexicano para cazar narco avionetas. Infobae. Recuperado de https://www.infobae.com/america/mexico/2020/02/01/siva-asi-funciona-el-sofisticado-sistema-del-ejercito-mexicano-para-cazar-narco-avionetas/

International Crisis Group (2013). Peña Nieto’s Challenge: Criminal Cartels and Rule of Law in México. Latin America Report (48). Bélgium

Keohane, R y Nye J. (2005). Poder, interdependencia y globalismo. En Borja A. (compilador), Interdependencia, cooperación y globalismo. Ensayos escogidos de Robert Keohane (pp. 373-452). México: Centro de Investigación y Docencia Económicas.

Márquez, G., y Meyer, L. (2010). Del autoritarismo a la democracia frágil, 1985-2010. En Nueva Historia General de México (pp. 747-792). México: El Colegio de México.

Medellín, A. (1 de junio de 2018). Los Embraer 145 de la Fuerza Aérea Mexicana en la última etapa de overhaul. Defensa.com. Recuperado de https://www.defensa.com/mexico/embraer-145-fuerza-aerea-mexicana-ultima-etapa-overhaul

Medellín, J. (31 de octubre de 2019). La nueva estrategia de vigilancia e intercepción de la Fuerza Aérea Mexicana. Defensa.com. Recuperado de https://www.defensa.com/mexico/nueva-estrategia-vigilancia-intercepcion-fuerza-aerea-mexicana

Memorándum de Entendimiento entre la SEDENA de México y el MINDEFENSA de Colombia para el intercambio de información y capacitación en materia de interdicción/interceptación aérea (2015).

Ministerio de Defensa Nacional. (22 de noviembre de 2016). Fuerza Aérea Colombiana. Inicio del ejercicio binacional simulado de interdicción aérea. Recuperado de https://www.fac.mil.co/inicio-del-ejercicio-binacional-simulado-de-interdicci\%C3\%B3n-a\%C3\%A9rea-mexcol-i

Ministerio de Defensa Nacional. Fuerza Aérea Colombiana (2018). Logros FAC 2006-2018 y Retos FAC 2018. Recuperado de https://www.justiciamilitar.gov.co/irj/go/km/docs/Mindefensa/Documentos/descargas/ Sobre_el_Ministerio/RendicionCuentas/2018/FAC/LogrosFAC2018. pdf 
National Institute of Drug Abuse. (2013). Tendencias nacionales. Encuesta Nacional sobre el Uso de Drogas y la Salud. Recuperado de https://www. drugabuse.gov/es/publicaciones/drugfacts/tendencias-nacionales

National Institute of Drug Abuse. (2019). DrugFacts: El fentanilo. Recuperado de https://www.drugabuse.gov/es/publicaciones/drugfacts/el-fentanilo

Noticieros Televisa. (10 de febrero de 2020). SEDENA interceptó avioneta con droga en la carretera Bacalar - Mérida [Archivo de video]. Recuperado de https://www.youtube.com/watch?v=yM7Y8R49ji0

Organización de Estados Americanos [OEA]. (2014). Lecciones Aprendidas en la lucha contra el Narcotráfico Fuerza Aérea Colombiana. Comisión Interamericana para el Control del Abuso de las Drogas. Quincuagésimo Secto Período Ordinario de Sesiones. 19 al 21 de noviembre de 2014. Guatemala.

Palacios, M., y Serrano, M. (2010). Colombia y México: Las violencias del narcotráfico. En: A. Alvarado, y M. Serrano (coordinadores), Los grandes problemas de México (XV). Seguridad nacional y seguridad interior (pp. 105-154). México: El Colegio de México. Recuperado de http://cei.colmex.mx/Estudios\%20Violencia\%20México\%20Materiales\%20recibidos/Grandes\%20problemas/Cap\%C3\%ADtulo\%204\%20(Serrano\%20 y\%20Palacios).pdf

Patón, N., Gallón, N., y Castrillón, D. (17 de abril de 2019). La corrupción en Venezuela ha creado una superautopista de cocaína a EE. UU. CNN en español. Recuperado de https://cnnespanol.cnn.com/2019/04/17/ la-corrupcion-en-venezuela-ha-creado-una-superautopista-de-cocaina-a-ee-uu/

Pérez, A. L. (2015). Mares de cocaina. Las rutas náuticas del narcotráfico. México: Grijalbo.

Quintero, H. (2018). Las fronteras no adyacentes, como solución al tráfico aéreo ilegal. En Fuerza Aérea Colombiana, Victorias desde el aire. La Fuerza Aérea Colombiana y el termino del conflicto armado (pp. 183-201). Volumen I. Bogotá.

Ravelo, R. (2016). En manos del narco. El nuevo rostro del crimen y su relación con el poder. México: Ediciones B.

Ruiz, M. (2014). Modernización de la Fuerza Aérea Mexicana (1980-2000). En: LXII Legislatura Cámara de Diputados y Secretaría de la Defensa Nacional. Fuerza Aérea Mexicana. La Aviación Militar un Siglo de Historia (1915-2015). México. 
Secretaría de la Defensa Nacional [SEDENA]. (2007a). Primer Informe de Labores. Recuperado de http://www.sedena.gob.mx/pdf/informes/primer_informe_labores.pdf

Secretaría de la Defensa Nacional [SEDENA]. (2007b). Directiva para el Combate Integral del Narcotráfico 2007-2012. SEDENA. México.

Secretaría de la Defensa Nacional [SEDENA]. (2015). Manual de Organización y Funcionamiento del Cuartel General de la Fuerza Aérea Mexicana. México: SEDENA.

Secretaría de la Defensa Nacional. [SEDENA]. (2018). Informe de Rendición de Cuentas de la Conclusión de la Administración 2012-2018. México: SEDENA.

Secretaría de la Defensa Nacional [SEDENA]. (2019). Datos Abiertos. Resultados de las operaciones en atención al Narcotráfico. México.

Secretaría de la Defensa Nacional [SEDENA]. (2020a). Primer Informe de Labores 2018-2019. México. Recuperado de http://www.sedena.gob.mx/ pdf/informes/primer_informe_labores.pdf

Secretaría de la Defensa Nacional [SEDENA]. (2020b). Organigrama de la Secretaría de la Defensa Nacional (SEDENA). Plataforma Nacional de Transparencia. Recuperado de https://consultapublicamx.inai.org.mx/ vut-web/faces/view/consultaPublica.xhtml\#tarjetaInformativa

Semana. (20 de agosto de 1990). Narcotráfico y CIA. SEMANA. Recuperado de https:/www.semana.com/mundo/articulo/narcotrafico-cia/13757-3

Semana. (8 de noviembre de 2018). Los narcomercenarios colombianos en México. SEMANA. Disponible en: https://www.semana.com/nacion/articulo/mercenarios-colombianos-entrenan-integrantes-de-carteles-mexicanos/579046

Subsecretaría de Lucha contra el Narcotráfico. (2016). Manual Básico de Precursores Químicos. Recuperado de https://www.mpf.gob.ar/procunar/files/2016/11/PRECURSORES-QUÍMICOS-Manual-básico.pdf

Tickner, A. (2016). Exportación de la seguridad y política exterior de Colombia. Friedrich Ebert Stiftung. Colombia.

Valdés, G. (2013). Historia del narcotráfico en México. México: Aguilar.

Webinfomil. (28 de mayo de 2017). Fuerzas Aéreas de Colombia y México realizaron ejercicio simulado de interdicción Mexcol II. Recuperado de http://www.webinfomil.com/2017/05/fuerzas-aereas-de-colombia-y-mexico.html 